\title{
Standard Test Methods for Rating of Solar Reflectance of Built-Up Surfaces and Potential Use of Satellite Remote Sensors
}

\author{
Sofia Costanzini (D, Chiara Ferrari (D), Francesca Despini and Alberto Muscio *(D) \\ Department of Engineering Enzo Ferrari, University of Modena and Reggio Emilia, Via Vivarelli 10, \\ 41125 Modena, Italy; sofia.costanzini@unimore.it (S.C.); chiara.ferrari@unimore.it (C.F.); \\ francesca.despini@unimore.it (F.D.) \\ * Correspondence: alberto.muscio@unimore.it
}

Citation: Costanzini, S.; Ferrari, C.; Despini, F.; Muscio, A. Standard Test Methods for Rating of Solar Reflectance of Built-Up Surfaces and Potential Use of Satellite Remote Sensors. Energies 2021, 14, 6626. https://doi.org/10.3390/en14206626

Academic Editor: Jesús Polo

Received: 4 September 2021

Accepted: 9 October 2021

Published: 14 October 2021

Publisher's Note: MDPI stays neutral with regard to jurisdictional claims in published maps and institutional affiliations.

Copyright: (c) 2021 by the authors. Licensee MDPI, Basel, Switzerland. This article is an open access article distributed under the terms and conditions of the Creative Commons Attribution (CC BY) license (https:/ / creativecommons.org/licenses/by/ $4.0 /)$.

\begin{abstract}
More and more attention is being paid to the solar reflectance of built-up surfaces due to its influence on the summer heating of buildings and urban areas and the consequent effects on energy needs for air conditioning, as well as on the peak load of the electric grid. Several standard test methods are available for measuring solar reflectance in the laboratory or in the field, based on different devices and approaches. A convergence of some methods has been achieved by rating programs in the U.S. and, more recently, in Europe and other areas. However, laboratory or field measurements are impractical for characterizing a large number of urban surfaces-whether it is for identifying critical issues, developing policies, or verifying compliance with building requirements. In this regard, satellite remote sensors have recently become available, through which it is possible to estimate the reflectance of roof and pavement surfaces thanks to a spatial resolution that is suitable for identifying and characterizing individual built-up surfaces. In the present paper, the most-used standard test methods for rating of solar reflectance are reviewed. Subsequently, some publicly accessible satellite sensors are examined, through which comparable measurements could be obtained.
\end{abstract}

Keywords: albedo; building cooling; certification; cool pavement; cool roof; performance rating; remote sensing; solar reflectance; standard test method; urban heat island

\section{Introduction}

Due to the well-known urban heat island effect [1,2], cities are significantly warmer than the surrounding suburbs. Therefore, more and more attention is being paid to solar reflectance of built-up surfaces, i.e., the ratio of reflected to incident solar radiation; it must be, and remain, as high as possible over time, so that most of the incident radiation is reflected back towards the celestial vault. The absorption and transfer of heat to the near ground air and/or to inhabited spaces is thus avoided. In fact, it is widely accepted that 'cool' built-up surfaces with high solar reflectance are among the most effective means to counter the overheating of single buildings and entire urban areas, mitigating its impact on energy needs for building cooling and the peak load of the electric grid. Lightly colored, highly reflective 'cool roofs' can reduce cooling loads by $18-93 \%$ in air-conditioned buildings, and peak cooling demand by 11-27\% [3]. 'Cool color' coatings, more reflective in the near-infrared in comparison to conventionally pigmented coatings with the same color, have also been developed [4,5]. Moreover, pavements cover a large fraction of urban areas; therefore, solar reflective 'cool pavements' can also contribute significantly to lower temperatures in the urban environment [6]. In general, reflective surfaces can replace darker materials during routine maintenance of roofs and roads [1]. After decades of research and development, a wide range of cool coatings for conventional construction materials have been made commercially available [7,8]. Furthermore, several innovative solutions are under development. For example, directionally reflective materials are being investigated for building façades, in order to let solar radiation emerge from urban canyons $[9,10]$. 
Thermochromic coatings change color with temperature and thus have a different solar absorption between the cold season and the hot season [11]. Fluorescent materials can re-emit through photoluminescence a portion of the absorbed solar irradiation that is added to the release of heat by convection and thermal radiation [12].

A term of comparison is needed between different solar reflective products of the same type or for similar uses. It is also useful to assess the performance and cost-effectiveness of innovative solutions with respect to conventional ones. Based on what was previously illustrated, solar reflectance can clearly be such a term of comparison. Indeed, there is another relevant surface property: thermal emittance, or emissivity. It represents the energy that a surface returns to the sky by emitting long-wave infrared radiation, in the range between 5 and $50 \mu \mathrm{m}$ at ambient temperature, divided by the maximum theoretical emission at the same surface temperature, i.e., the blackbody radiation. It is completely decoupled from solar reflectance as this is related to radiation in the range between 0.3 and $2.5 \mu \mathrm{m}$. For most of the built-up surfaces, however, thermal emittance falls within a relatively narrow range around 0.9 , so solar reflectance is the crucial performance parameter. The combined effect of solar reflectance (which rules the absorbed fraction of solar energy) and thermal emittance (which affects the energy returned to the celestial vault by thermal radiation alongside that exchanged with the air by convection) can also be expressed through the solar reflectance index (SRI) [13,14].

The solar reflectance of construction materials and coatings can be rated to demonstrate compliance with minimum requirements. The main rating program in current use is that of the Cool Roof Rating Council (CRRC) of the U.S., a non-profit organization created in 1998 to develop methods for evaluating and labeling the performance of solar reflective roofing products (i.e., cool roofs) and to disseminate the information to all interested parties $[15,16]$. The CRRC specifies the standard test methods for assessment of solar reflectance, thermal emittance and SRI, coordinates and monitors a network of independent ISO/IEC 17,025 accredited test laboratories, and manages a public database of the rated products. A similar organization, the European Cool Roof Council (ECRC), was established in 2014, and is building up a rating program targeted at European buildings [17]. It must be underlined that both the CRRC and ECRC do not specify minimum requirements. In the U.S., these are specified in building energy codes such as Title 24 of the California Building Energy Efficiency Standards [18] — as well as in model codes adopted by states and municipal governments such the International Energy Conservation Code (IECC) [19] and the ANSI/ASHRAE/IES Standard 90.1 [20], or in standards for green building design, construction, operations and performance such as the worldwide adopted LEED [21]. Requirements on solar reflectance and/or SRI have also been set in many developed countries other than the U.S., e.g., in Italy for new buildings or to obtain economic incentives for renovation of existing buildings. In China, cool roofs and walls have been given 'credits' in the national residential design standard, where a 'credit' is a trade-off that allows greater flexibility in design of the building, for example permitting the use of less insulation [22].

Rating of 'cool' materials is performed by standard test methods, mostly developed in the U.S. by ASTM but often adopted elsewhere with null or minimal modifications. The most used test methods are described in the following sections. In general, a convergence has been achieved on calculating reflectance as the average of the reflectivity spectrum measured in the laboratory, weighted by a reference solar spectrum. The U.S. currently differs from most other countries in that the requirements on solar reflectance and SRI regard aged rather than brand new products. In other words, standard test methods are applied to samples that have been subjected to ageing. The reason is that a strong degradation of highly reflective surfaces can be promoted by ultraviolet radiation, high temperatures, moisture, and above all soiling, due to particulate deposition or biological growth [23]. Long-term natural ageing is required for at least three years in different weathering test farms, following a specific program managed by CRRC [15]. An accelerated soiling method was also developed [24] and eventually made usable as the ASTM D7897 Standard Test Method [25]. According to this method, samples are subjected to several 
cycles, in which they are sprayed by a properly formulated liquid mixture, warmed, dried, and irradiated by UV lamps. In about three days, it is possible to achieve a surface condition similar to that obtained after years of natural ageing. Measurements after accelerated ageing provide provisionary values of solar reflectance and SRI, which can be used for performance rating while other samples are subjected to natural ageing. The adaptation of this method to European urban areas, generally more polluted than those in the U.S., has been recently investigated [26].

The industry does not readily accept long-term natural ageing, as the time needed may significantly delay the commercialization of new products. Moreover, it is possible to expose only a limited number of relatively small samples in weathering test farms, where they could be destroyed by a hailstorm or a tornado, or face atypical situations such as season anomalies, a fire in an adjacent location, or nearby dusty construction work. On the other hand, accelerated ageing may not work properly on all types of material and solution; moreover, it does not take into account biological growth. It is also difficult to reduce large building elements such as roof tiles to small samples, suitable for natural or accelerated ageing. Laboratory measurements are, however, impractical for characterizing a very large number of urban surfaces, whether for identifying critical issues, verifying compliance with building requirements, or developing policies. In this regard, aerial and satellite remote sensors have recently become available, by which the reflectance of roof and pavement surfaces could be efficiently assessed thanks to a spatial resolution adequate for identifying and characterizing single built-up surfaces. More specifically, reflectance can be assessed in several wavebands over the solar range, with spatial resolution adequate to identify and characterize specified surfaces-also taking into account the vapor and pollutant content of the interposed atmosphere. Multiband (blue, green, red, and near-infrared) aerial images with spatial resolutions of $1 \mathrm{~m}$ were used to derive the solar reflectance of roofs in seven California cities [27]. Building materials were identified from their spectral signature of reflectance in the solar radiation range, obtained from hyperspectral aerial images [28]. Aerial data such as orthorectified images were used to identify urban surfaces and then to retrieve the solar reflectance of these surfaces by correlation with on ground measurements [29]. Maps of solar reflectance of built-up surfaces were exploited in the Weather Research and Forecasting (WRF) climatic model to estimate the improvements attainable by converting the current stock of roofs to 'cool roofs' with higher solar reflectance [30]. Satellite data were also used to retrieve solar reflectance maps as an alternative to airborne data, but their use was mostly limited to climate models or agricultural applications [31], due to their inadequate spatial resolution. Nonetheless, the recent availability of images from multispectral sensors with resolutions around $1 \mathrm{~m}$ such as the WorldView commercial satellites of DigitalGlobe Inc. has made satellite images a cost-effective alternative to airborne images. These are usable for classification of single urban surfaces at building level and, thereafter, for retrieval of their solar reflectance [32].

In this paper, the most used methods for rating of solar reflectance are reviewed. Subsequently, publicly accessible satellite sensors, through which comparable solar reflectance measurements could be achieved, are examined. In the end, exploratory results are briefly presented about the comparison between field and remote measurements on built-up surfaces.

\section{Standard Test Methods and Instruments for Solar Reflectance Measurement}

The relative amount of solar radiation reflected by a surface is specified as solar reflectance, or albedo. The latter term sometimes refers only to visible sunlight (Vis), while the former generally refers to the entire spectrum of solar radiation, including near-infrared (NIR) and ultraviolet (UV) radiation. However, the scientific and technical communities consider albedo and solar reflectance synonymous, with both referring to the entire solar spectrum. Solar reflectance is usually expressed as a value between zero, for a surface absorbing all incoming radiation, and one, for a perfect reflector-or as a percentage between 0 and $100 \%$. For an opaque surface, solar reflectance is complementary 
to solar absorptance - that is, the ratio of absorbed to total incident solar energy. Several instruments are available for its measurement, in the laboratory on in situ, according to several standard test methods.

\subsection{Spectrophotometer}

A spectrophotometer allows continuous measurement of spectral reflectance over the range of interest - that is, the amount of radiation reflected at each wavelength, whatever its source is. The range of interest for solar radiation is between $300 \mathrm{~nm}$ and $2500 \mathrm{~nm}$. The distribution of spectral reflectance over this range, in which $99 \%$ of solar radiation falls, is often referred to as the solar reflectance spectrum. Spectral reflectivity, or even reflectivity alone, is sometimes used synonymously with spectral reflectance. However, the National Institute of Standards and Technology (NIST, at the time the National Bureau of Standards, NBS) recommended reserving the ending '-ivity' for radiative properties of pure and perfectly smooth materials, and to use the ending '-ance' for rough and contaminated surfaces [33]. Built-up surfaces clearly fall into the latter category. The reflectance spectrum can also be expressed using frequency rather than wavelength, as their product is a constant, equal to the velocity of light in the air. However, it is common in the field of building energy to refer to wavelength.

The solar reflectance $\rho_{\text {sol }}$ is calculated by averaging over the range of interest the measured spectral reflectance $\rho_{\lambda}$, weighted by the sun spectral irradiance at the earth surface $I_{\text {sol, } \lambda}\left(\mathrm{W} /\left(\mathrm{m}^{2} \mathrm{~nm}\right)\right)$ :

$$
\rho_{s o l}=\frac{\int_{300}^{2500} \rho_{\lambda} I_{s o l, \lambda} d \lambda}{\int_{300}^{2500} I_{s o l, \lambda} d \lambda}
$$

$I_{s o l, \lambda}$ is the amount of solar radiation at the considered wavelength $\lambda(\mathrm{nm})$ that passes through the atmosphere and reaches the earth surface.

A spectrophotometer is an instrument that measures light. It is a complete system including a light source, a means to collect radiation that has interacted with the tested sample, and a spectrometer sensor to measure that radiation. Light is not limited to the visible range but is more widely understood as electromagnetic radiation. The term "photo" indicates that the instrument quantitatively measures radiation intensity with wavelengths. In the common 'scanning spectrophotometer', a monochromator containing a diffraction grating is scanned stepwise so that radiation intensity is measured at each wavelength step. In the single-beam spectrophotometer, the spectral reflectance is determined comparing the radiation intensities measured after and before the tested sample is substituted to a reference sample. In the double-beam spectrophotometer, the spectral reflectance is determined comparing the radiation intensities between two light paths-one containing the test sample and the other a reference sample. Double beams are more complex than single beams but are less sensitive to fluctuations in the light source. Reference materials for solar reflectance measurements are magnesium oxide $(\mathrm{MgO})$, barium sulfate $\left(\mathrm{BaSO}_{4}\right)$ and various proprietary types of polytetrafluoroethylene (PTFE), such as the widely used Spectralon [34]. All of these are diffuse reflectance materials with a high spectral reflectance over the entire range of solar radiation.

A real surface has a behavior somewhere between a specular reflector, which reflects light beams with the same angle of incidence (Figure 1a), and a diffuse reflector, which reflects in all directions (Figure 1b). A polished metal is an almost perfect specular reflector, while most built-up surfaces are rough and non-metallic - thus showing an almost diffuse behavior. In solar reflectance measurements aimed at providing data for energy balances of urban surfaces, the hemispherically reflected radiation (i.e., directly and diffusely refleted) must be detected. This is achieved by means of an integrating sphere (Figure 1c)-a component of the spectrophotometer consisting of a hollow spherical cavity with its inner surface covered with a diffuse reflective coating, typically of the same materials as the reference samples $\left(\mathrm{MgO}, \mathrm{BaSO}_{4}, \mathrm{PTFE}\right)$. Radiation reflected by the tested sample to any point of the cavity surface is distributed equally by multiple scattering reflections to all other 
points, including the part covered by the photometer detector. The larger the diameter of the integrating sphere, the larger the allowed size of the sample port and the sample itself.

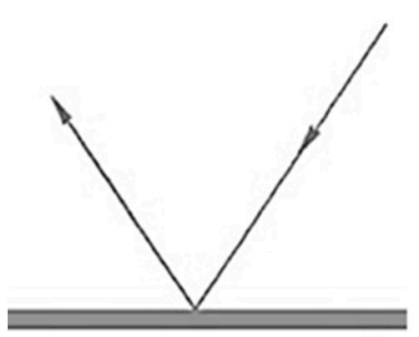

(a)

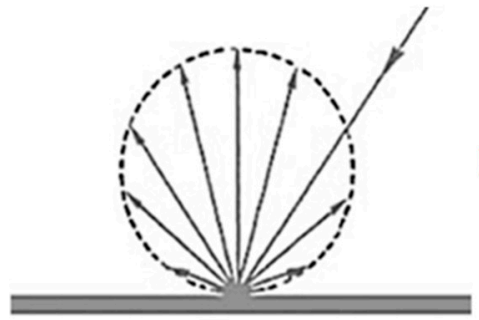

(b)

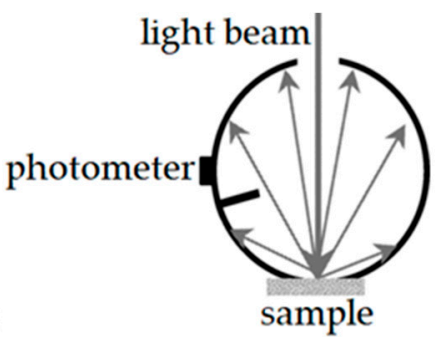

(c)

Figure 1. Specular reflector (a), diffuse reflector (b), and integrating sphere (c).

ASTM E903 [35] is a widely appreciated standard test method that relies upon the use of a spectrophotometer with an integrating sphere to measure the spectral reflectance of the test sample over the entire range from $300 \mathrm{~nm}$ to $2500 \mathrm{~nm}$. The first version of the standard dates back to 1996 and was implemented into the CRRC rating program in 1998. Entering into details, it is used to measure near normal-hemispherical solar reflectance, i.e., reflectance with irradiance almost normal to the sample surface and flux leaving the surface collected, in order to detect the radiation intensity, over an entire hemisphere. A double-beam spectrophotometer is recommended, as well as an integrating sphere with a minimum diameter of $150 \mathrm{~mm}$. The acquired spectrum of solar reflectance is finally averaged over the measurement range, being weighted by a spectrum of solar irradiance at the earth surface according to Equation (1). Some solar spectra are provided in previous studies [35]; nevertheless, the choice of the reference spectrum is not so obvious.

The solar spectral irradiance depends on the position of the sun in the sky and, therefore, on the latitude, the time of the year and the time of day. It also depends on the solid angle it comes from, distinguishing between:

- beam normal or direct normal, i.e., the solar flux coming from a solid angle covering the sun's disk and reaching a surface perpendicular to the axis of the above-mentioned solid angle;

- $\quad$ direct-from the sun's disk onto a surface with a given inclination and orientation;

- direct and circumsolar - which includes the direct radiation scattered by the atmosphere so that it seems to come from an area of the sky immediately adjacent to the sun's disk, whose aperture is related to the aerosol optical depth [36];

- $\quad$ diffuse - over the entire hemisphere facing the earth surface (excluded direct); and

- global - which includes direct and diffuse.

The fraction of extraterrestrial radiation that reaches the earth surface is affected by the air mass, i.e., the mass of atmospheric air in the observer-sun path divided by the mass of atmospheric air that would be present if the observer was at sea level, at standard atmospheric pressure, and the sun was directly overhead (with air mass $=1$ assigned to such a path). It is also affected by the content of water vapor in the atmosphere and the content of particle suspensions such as fog, clouds, particulate, and dust. Finally, the intensity of radiation reaching a built-up surface depends on the orientation and inclination of such a surface.

The sensitivity of the weighted radiative properties to different solar irradiance spectra was already investigated in the eighties of the past century, leading to the recommendation of a single solar spectrum for use as a standard [37]. A spectrum used in the U.S. for various purposes was specified in the ASTM E891 standard [38], whose first release dates back to 1987. This is the one initially recommended by ASTM E903 in its 1996 version, and it was therefore adopted by the Cool Roof Rating Council. It is specified for air mass 1.5, beam normal solar irradiance and hazy sky at the latitude of the U.S. It was probably intended for sun-tracking photovoltaic panels, so it may be a less appropriate 
choice while considering the thermal behavior of a built-up surface irradiated by the sun. Moreover, it was withdrawn and the current ASTM E903 version recommends data reported in the ASTM G173 standard [39] for air mass 1.5 and direct normal radiation (including circumsolar radiation in a solid angle centered on the sun's disk and with an aperture half-angle of $2.9^{\circ}$ ), or for global radiation on a $37^{\circ}$ tilt south-facing surface. These spectra also seem aimed at the analysis of photovoltaic panels, respectively sun tracking or fixed-again at the latitude of the U.S. More recently, the air mass 1 global horizontal spectrum (AM1GH) has been recommended [40,41]. It comprises both direct and diffuse radiation on a horizontal surface, with the sun directly overhead in a clear sky. The use of AM1GH allows the measuring of solar reflectance under conditions closer to the annual peak of solar heat gain, from which air conditioning systems are typically sized in terms of peak cooling load. Moreover, peak load of the electric grid and health issues mostly arise for the peak cooling load. AM1GH was also shown to apply well not only to horizontal surfaces at the latitude of the U.S., but also to moderately pitched roofs, and it is expected to work well between $49^{\circ} \mathrm{S}$ and $49^{\circ} \mathrm{N}$ [40]. In the EU, a similar spectrum for air mass 1 is indeed specified in EN 410 [42] for analysis of glazed elements.

Table 1 summarizes the percent energy content of the previously mentioned solar spectra in the ultraviolet (UV), visible (Vis, commonly set between $400 \mathrm{~nm}$ and $700 \mathrm{~nm}$ for analyses on solar reflective materials), and near-infrared (NIR) ranges. A clearly varying spectral content is evident. In particular, the air mass 1.5 beam normal spectrum from ASTM E891 has a NIR content as high as 58\%, whereas the NIR content is slightly below $50 \%$ for air mass 1 global horizontal spectra such as AM1GH, and that in EN 410. As a result, a 'selective' material that is highly absorbing in the visible range, e.g., due to a dark color mandatory for the considered surface, but at the same time highly reflective in the NIR range, would be rated differently because of the selected reference spectrum. Absolute discrepancy in solar reflectance measurements on a set of samples with different colors was found to be as high as 0.02 on a reflectance scale from 0 to 1 [43]—an amount scarcely relevant for energy balances, but more significant for the comparison of competing solar reflective products. Fairness of comparison is the very reason why the Cool Roof Rating Council still prescribes or recommends, for product rating, the use of the beam normal spectrum from ASTM E891 [15,16], in conjunction with both ASTM E903 and another widely used standard test method specified in ASTM C1549 [44], illustrated in the next section. The same approach is followed [17] by the European Cool Roofs Council.

Table 1. Energy content of alternative solar spectra in the ultraviolet (UV), visible (Vis), and near-infrared (NIR) ranges.

\begin{tabular}{ccc}
\hline Solar Spectrum & Source of Data & $\begin{array}{c}\text { UV/is/NIR } \\
\text { Energy Content (\%) }\end{array}$ \\
\hline Air mass 1 global horizontal irradiance, clear sky & EN 410:2011 [42] & $6.5 / 45.0 / 48.5$ \\
Air mass 1 global horizontal irradiance (AM1GH), clear sky & NREL SMARTS 2.9.5 [45] & $6.5 / 45.0 / 48.5$ \\
Air mass 1.5 global irradiance on a 37 tilt south facing surface, & ASTM G173-03(2020) [39] & $4.5 / 43.5 / 52.0$ \\
clear sky & ASTM G173-03(2020) [39] & $3.3 / 42.2 / 54.5$ \\
Air mass 1.5 direct normal+circumsolar irradiance, clear sky & ASTM E897-87(1992) [38] & $2.8 / 39.2 / 58.0$ \\
Air mass 1.5 beam normal irradiance, hazy sky & & \\
\hline
\end{tabular}

\subsection{Solar Reflectometer}

A spectrophotometer provides the most accurate measurement of solar reflectance. However, it is impractical for in situ use due to the size and delicateness of the instrument. Moreover, only flat and smooth samples with a surface of a few square centimeters can be tested. In view of that, the solar spectrum reflectometer, as described in the ASTM C1549 standard test method [44], was developed. This is a portable instrument which measures the radiation reflected by a test surface at an angle of $20^{\circ}$ from the normal to the surface. A cavity in the measurement head (Figure 2a) is painted with a highly reflecting material. Inside the head, a tungsten halogen lamp diffusely irradiates the cavity surface and, consequently, through an opening with a $2.5 \mathrm{~cm}$ diameter, the tested sample 
is placed against the head and closes that opening. Reflected light is measured with an assembly of four detectors. Each detector is equipped with color filters to concentrate its electrical response in a given wavelength range of the solar spectrum (Figure 2b). Weighting properly the outputs of the four detectors, the response is obtained for incident solar radiation with the most commonly used spectral distributions and a desired air mass (from 0 to 2). By reciprocity relations among reflectances, the instrument yields the total hemispherical reflectance for beam radiation incident at a $20^{\circ}$ angle from the normal to the surface. The instrument is calibrated with a black body cavity for zero-reflectance, and with reference samples of known radiative properties for higher reflectance values. A cross comparison with measurements performed according to ASTM E903 by means of a scanning spectrophotometer gave results in agreement within \pm 0.02 on a reflectance scale from 0 to 1 [46].

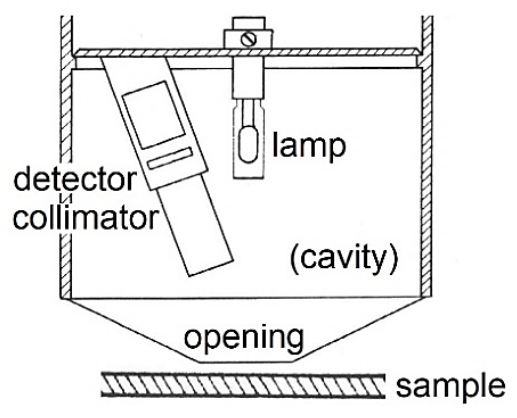

(a)

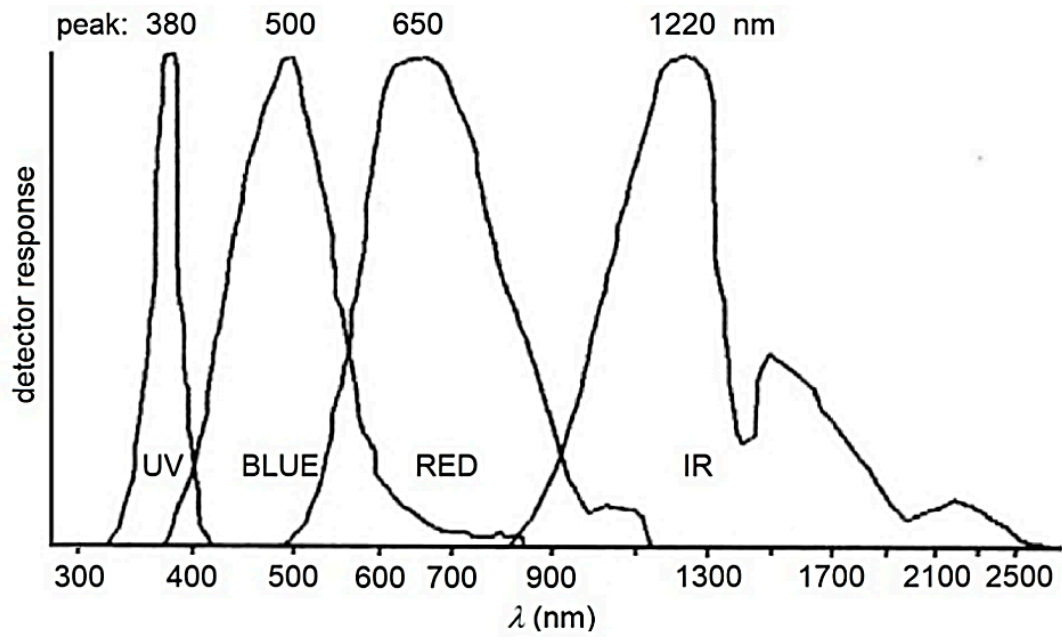

(b)

Figure 2. Solar spectrum reflectometer head (a), sketch redrawn from [47] and sensitivity curves of the embedded detectors (b); patterns retraced from [48].

Thanks to the ease of use and quickness of measurement by the solar reflectometer, modifications of the methods were also developed to measure the reflectance of variegated (in color) and/or textured surfaces, obtained by averaging a large number of randomly distributed reflectometer readings [49-51]. These modifications are now incorporated in rating standards $[15,16]$.

Both the spectrophotometer and the solar spectrum reflectometer are well suited to test flat samples. Nonetheless, an approach was numerically developed [52] and verified [53] to correct measurements performed on flat samples and calculate the slight decrease of solar reflectance that takes place on different types of profiled roof surfaces such as high-profile tile, metal box rib, standing seam, etc., due to multiple reflection-absorption. An approach was also developed to test samples with a large-radius cylindrical surface [54].

To the authors' best knowledge, there is only one commercial instrument that complies with ASTM C1549 [55]. In its latest version (v6), two 'virtual' detectors were added to the four actual detectors centered on UV, Blue, Red and IR ranges, in order to better match the various solar irradiance spectra. The two virtual detectors are implemented by resampling the Red and IR detectors at a much lower color temperature of the lamp source [56]. Moreover, rather than having fixed detector weightings, a custom set of weightings for each produced instrument is generated to best fit each solar irradiance spectrum, using a very large number of reference samples tested by different spectrophotometers [56]. Nevertheless, to promote a fair comparison with products rated through previous versions of the instrument, the CRRC recommends using only the four given detectors for product rating, as well as the fixed weightings originally applied to match the beam normal air 
mass 1.5 spectrum from ASTM E891 [15,16]. As a matter of fact, this approach was found to slightly increase the solar reflectance readings and thus penalize samples tested with the more advanced instrument setup and weighting coefficients. The largest increases were observed for spectrally selective cool colors in tests performed with air mass 1 spectra [53].

ASTM E903 and ASTM C1549 are equivalent test methods in the rating schemes of the CRRC [15,16] and ECRC [17], provided that the same spectrum from ASTM E891 [38] is used. The first method is best suited for laboratory use and research analyses, while the second one is targeted at in situ testing. However, solar spectrum reflectometers also seem to be largely used in the laboratory thanks to their speed of use and reasonable accuracy.

\subsection{Pyranometer}

A pyranometer measures the total radiant energy per unit time and unit surface area that falls onto the sensor surface. Spectrophotometers and reflectometers rely upon an embedded light source. Instead, the pyranometer-based technique specified in the ASTM E1918 standard test method [57] relies upon actual solar radiation. The technique consists of taking readings from a pyranometer while it faces the sun, and immediately afterwards, while it faces the surface, in order to be characterized. The receiver of a pyranometer is a thermopile sensor coated with a black absorbent coating that absorbs the global (direct and diffuse), incident or reflected, solar radiation. The thermopile sensor, which is typically covered by a transparent dome, generates a voltage in response to the heat absorbed. ASTM E1918 recommends a double-dome design, with two thermopile-dome assemblies contemporarily facing upwards and downwards, in order to minimize the disturbing effects of convection inside the dome. Pyranometers and solar spectrum reflectometers were found to provide almost identical values of solar reflectance [48], whereas a slightly looser agreement from 0.015 to 0.043 is reported between measurements according to ASTM E1918 and ASTM C1549 with air mass 1 global horizontal solar irradiance (AM1GH) [53]. Using ASTM C1549 with the air mass 1.5 beam normal spectrum from ASTM E891 further increased the discrepancy.

The solar altitude must be high enough to get a good response in both the upwards and downward positions of the pyranometer. In this regard, ASTM E1918 recommends, for application on horizontal or low-slope roofs, a sun angle from the normal to the tested surface lower than $45^{\circ}$. As a result, there is a time window in which measurements can be performed, whose width depends on latitude and is larger in the summer, but shrinks and may become null in winter. The pyranometer sensor must be mounted at a height of $50 \mathrm{~cm}$ above the analyzed surface to minimize the effect of its shadow. The test area is a large circle at least $4 \mathrm{~m}$ in diameter, but it can be made as small as $1 \mathrm{~m}^{2}$ with non-standard modifications of the method $[58,59]$. The large test area however provides a unique advantage in that aggregates variegated in color and irregular or profiled surfaces can be easily tested in situ, obtaining their effective reflectance. In these cases, the CRRC accepts ASTM E1918 as a test method for product rating $[15,16]$. However, the solar spectrum is relative to the place and time of the test and is not standard, therefore ASTM E903 or ASTM C1549 may be preferable in terms of fairness of product comparison whenever they can be used.

\subsection{Non-Standard Test Methods for Advanced Solar-Reflective Materials}

Directional reflective materials (DRMs) have been introduced to the roofing market. They can have a profiled surface that reflects solar radiation when the sun is high in the sky, and absorbs it when the sun is low, i.e., in winter [60]. DRMs can also be designed to look dark from the street, e.g., to cope with color requirements, and light from the sky, toward which they reflect solar radiation. Applying standard test methods such as ASTM E903 [35], C1549 [44], or E1918 [53] to DRMs is impractical. Therefore, three choices of metric for product rating were proposed [60], based on a mathematical model and the actual reflectances of the dark and light-colored surface areas: a single reflectance value during a year with a good performance in winter; a single reflectance value during a year 
with a good performance in summer; and different reflectance in the summer and winter (preferred choice).

In an urban canyon formed by buildings that face each other, sunlight entering the canyon is almost completely absorbed by the building surfaces due to multiple reflectionabsorption effects-whichever is the reflectance of the façades. To mitigate the so-called urban canyon effect, retroreflective materials for façades are being investigated. One type can have a surface shape and finish that allows reflecting of the incident sunlight back to the sky. Retroreflective sheeting for traffic control has also been also tested [9]. These sheets are made of glass bead lenses embedded in a transparent binder and applied onto a reflective substrate. It was shown that a retroreflective vertical surface with solar reflectance of 0.60 could return $55 \%$ of incident sunlight to the sky, while a Lambertian (i.e., diffusely reflecting) surface with the same reflectance would reflect only $36 \%$ of sunlight skyward [10]. Applying standard test methods to retroreflective materials is again impractical. Therefore, their reflectance was tested by comparing the sample temperatures under sunlight to those of non-retroreflective reference specimens $[61,62]$. As an alternative, the angular distribution of spectral reflectance was assessed in the range of solar interest with a repositionable fiber-optic spectrophotometer [63,64]. A two-axis solar gonio-spectrophotometer was also used, in which the specimen could be tilted from $-90^{\circ}$ to $90^{\circ}$, with three photodetectors covering the entire solar range $[65,66]$. A repositionable photodetector with a broadband response over a significant part of the solar range and angles ranging from $-70^{\circ}$ to $70^{\circ}$ was used to measure the angular distribution of light reflected from a sample illuminated with a normally incident xenon-arc artificial solar light source [67]. As an alternative, a semicircular array of fixed photodiodes with broadband response was exploited, with angles ranging from $-90^{\circ}$ to $90^{\circ}$, and a xenon-arc artificial solar light source [68], or a blue, green, or red laser source [69].

Fluorescent materials such as quantum dots can re-emit light by photoluminescence. This provides an additional heat rejection mechanism in materials that rely on reflection alone; they show a potentially higher cooling capacity than conventional solar reflective materials with the same color [12]. Their effective solar reflectance was calculated by comparing their temperatures in the sun to those of non-fluorescent reference specimens [70].

\subsection{Accessory Measurement of Thermal Emittance and Calculation of the Solar Reflectance Index (SRI)}

In contrast to solar reflectance, on which this paper is focused, minimum values are seldom set for thermal emittance (also called infrared emittance, or emissivity). As already stated, this is the ratio of the energy that the considered surface emits toward the sky in the far infrared and the maximum theoretical emission at the same surface temperature. Like solar reflectance, it ranges from 0 to 1 (or 100\%). A low thermal emittance can cause a surface to overheat even if it is highly reflective, because the fraction of solar energy that is absorbed, however small, cannot be efficiently returned to the celestial vault.

The thermal emittance is measured by several techniques. Narrowing the field to standard test methods that can be applied to built-up surfaces, an emissometer for laboratory or in situ measurement of the total hemispherical emittance can be based on ASTM C1371 [71]. The emissometer embeds a differential thermopile, which consists of a blackcoated thermopile and another with a reflective coating. The emissometer head, in which both thermopiles are embedded, is warmed to provide the necessary temperature difference with respect to the tested sample. The differential thermopile signal is correlated to the heat flux exchanged by infrared radiation between the head and the sample surface after thermal equilibrium is achieved. The instrument is calibrated using two reference samples with high and low emittance. A widely used modification of the standard technique developed for thick samples with low thermal conductivity such as concrete, clay tiles, wood shingles, or insulation-backed membranes, is the 'Slide method' [72]. In this modification, the emissometer head is continuously moved over the sample to avoid warming it up. Both ASTM C1371 and the Slide method are included in the CRRC $[15,16]$ and ECRC [17] rating programs. The ECRC also accepts another standard test method, specified in EN 
15976 [73]. This was developed to measure the thermal emittance of low-emittance coatings for glazing; however, it can also be applied to opaque surfaces. It is conceptually analogous to ASTM C1371, with the difference that a thermal infrared (TIR) sensor of radiant heat flux is embedded in the emissometer head instead of the differential thermopile. Thanks to the quickness of response of such sensors, which do not require reaching of the thermal equilibrium of the head-sample system, the method can be used without modifications on thick samples made of non-conductive materials.

The thermal response of a surface due to the superposed effects of solar reflectance and thermal emittance is often given through the 'solar reflectance index' (SRI). This represents, in specified ambient conditions (air temperature, sky temperature, solar irradiance, wind velocity), the surface temperature decrease provided by the considered coating with respect to a reference black surface, divided by the surface temperature decrease provided by a reference highly reflective coating $[13,14]$. SRI is evaluated in percentage terms through the relationship [13]:

$$
\mathrm{SRI}=100 \cdot \frac{T_{b}-T_{s}}{T_{b}-T_{w}}
$$

$T_{S}(\mathrm{~K})$ is the thermal equilibrium temperature of the tested surface while it is irradiated by a reference solar flux $I_{\text {sol }}$ as high as $1000 \mathrm{~W} / \mathrm{m}^{2}$, the atmospheric air temperature $T_{\text {air }}$ is $310 \mathrm{~K}$, and the sky temperature $T_{\text {sky }}$ is $300 \mathrm{~K}$. Moreover, values of 5,12 , and $30 \mathrm{~W} /\left(\mathrm{m}^{2} \mathrm{~K}\right)$ are assigned to the convection heat transfer coefficient $h_{c}$, respectively corresponding to low $(<2 \mathrm{~m} / \mathrm{s}$ ), intermediate (between 2 and $6 \mathrm{~m} / \mathrm{s}$ ), and high (between 6 and $10 \mathrm{~m} / \mathrm{s}$ ) wind speed. Intermediate wind speed is the reference condition for product rating. $T_{b}(\mathrm{~K})$ and $T_{w}$ $(\mathrm{K})$ are the temperatures that are reached at thermal equilibrium by two reference surfaces: a black one with reflectance as low as 0.05 and the other white with reflectance as high as 0.80 - both with high emissivity $(\varepsilon=0.90)$.

The surface temperature $T_{s}$ (as well as $T_{b}$ and $T_{w}$ ) is calculated by iteratively solving the surface-heat balance at thermal equilibrium [13]:

$$
\left(1-\rho_{s o l}\right) I_{s o l}=\varepsilon \sigma_{0}\left(T_{s}^{4}-T_{s k y}^{4}\right)+h_{\mathcal{c}}\left(T_{s}-T_{a i r}\right)
$$

where $\sigma_{0}=5.67 \cdot 10^{-8} \mathrm{~W} /\left(\mathrm{m}^{2} \mathrm{~K}^{4}\right)$ is the Stefan-Boltzmann constant. This balance is based on the hypothesis of an adiabatic irradiated surface.

The calculation of SRI includes both solar reflectance and thermal emittance, as well wind conditions. Negative values or values higher than 100 can be obtained, as materials can exist with a poorer performance than the black reference surface, or superior to the white reference one. High values of solar reflectance and thermal emittance are contemporarily needed to keep the considered surface cool, unless the reflectance is very high (Figure 3). Generally speaking, it is worth mentioning that the emittance is usually around 0.9 for most built-up surfaces, being significantly lower only for metal surfaces with absent or very thin coating. 


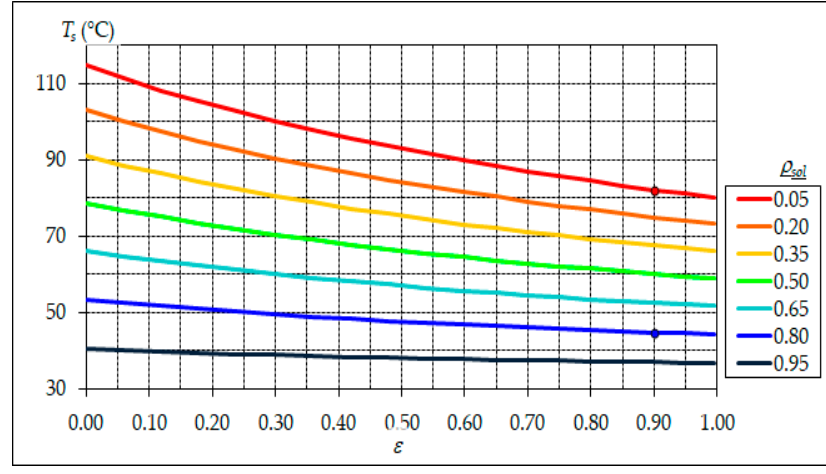

(a)

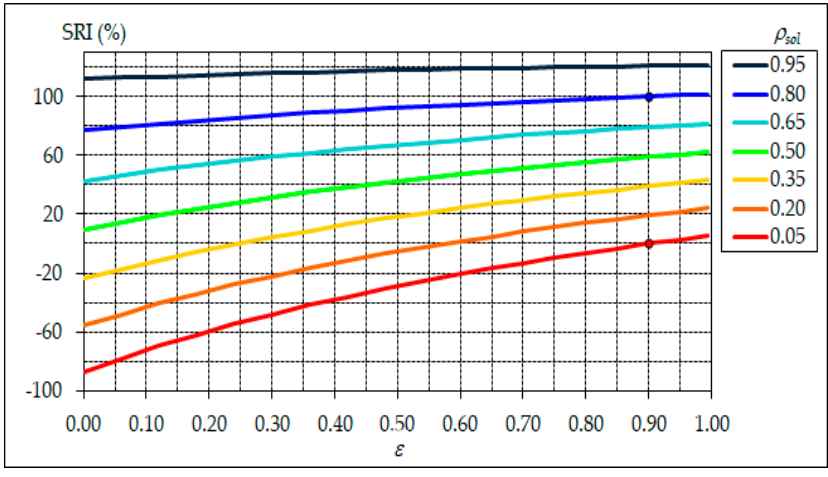

(b)

Figure 3. Surface temperature (a) and SRI (b) for reference ambient conditions and convection coefficient $h_{c}=12 \mathrm{~W} /\left(\mathrm{m}^{2} \mathrm{~K}\right)$, as a result of intermediate wind speed (i.e., between 2 and $6 \mathrm{~m} / \mathrm{s})$; blue and red dots are for the reference white $\left(\rho_{\text {sol, } w}=0.80\right.$, $\left.\varepsilon_{w}=0.90\right)$ and black $\left(\rho_{s o l, b}=0.05, \varepsilon_{b}=0.90\right)$ surfaces, respectively.

\section{Solar Reflectance from Satellite Data}

Passive remote sensing allows studying of the physical, geomorphological and geometric characteristics of the observed surfaces. Several satellite and aerial sensors for environmental monitoring are available, with different characteristics.

Remote sensing images in the thermal infrared bands are widely used to analyze the urban heat island phenomenon and its effects on the urban environment [74]. Thermal infrared (TIR) is the range of the electromagnetic spectrum between about 7 to $20 \mu \mathrm{m}$ that allows the analysis of the thermal state of surfaces. It is the range in which the observed surfaces mostly emit infrared longwave radiation towards the celestial vault, where it can be picked up by satellite or aerial detection systems [75]. TIR sensors usually provide images with a very low spatial resolution, i.e., a hundred meters or worse; thus, punctual analysis of the observed surfaces is difficult. In general, TIR images are useful for temperature calculation over large surface areas such as in the assessment of the urban heat island-for which a high spatial resolution is not needed. They are generally considered unsuitable for the recognition and distinction of urban surfaces [76].

A good spatial resolution is considered essential for studies aimed at the identification and characterization of city surfaces such as streets, buildings and urban parks, while spectral resolution has taken a second place. High spatial resolution images are needed to fully distinguish urban geometries in view of the diversity of surfaces present in an urban environment, which often show non-homogeneous optical characteristics. However, the problem that mostly afflicts remotely sensed images is the 'mixed pixel', that is, a pixel within which there are multiple features. A pixel is the elementary unit of digital images, including remote sensed ones. If there are different surfaces inside a single pixel, they will be incorrectly identified. This is an issue that principally affects low spatial resolution images. In particular, several studies have highlighted that, in an urban environment, a spatial resolution from 10 to $15 \mathrm{~m}$ can be useful to provide an overview of the urban area and land cover, while a resolution below $5 \mathrm{~m}$ is required to recognize individual objects [77]. Welch [78] and Jensen and Cowen [79] found a minimum spatial resolution between 0.5 and $5 \mathrm{~m}$ was required in order to identify buildings, while resolutions up to $30 \mathrm{~m}$ are sufficient to identify roads. In addition to the high spatial resolution needed to identify urban surfaces, a good spectral resolution is required to characterize them. In many cases, the four typically used wavebands—red, green, blue (RGB) and near-infrared (NIR)—can be exploited to characterize the different types of surfaces [80]. A larger number of bands, both in the visible and in the NIR, are however necessary to achieve a deep characterization, such as the composition and aging of the materials, the type of vegetation, etc. [80,81].

Currently there are several types of commercial and free aerial or satellite sensors, from which it is possible to acquire images for the study of urban surfaces. The limit of airborne sensors is undoubtedly an economic one. The organization of an air campaign 
requires a long time and high costs for the aircraft and personnel. On the other hand, satellites that provide images for free, such as Sentinel 2 of the European Space Agency, do not have a spatial resolution adequate for surface identification and characterization; therefore, it is necessary to access paid services of data acquisition. The number of useful satellite systems is relatively low, even if it is increasing together with the resolution and affordability of remotely sensed data. The currently operational and most used satellite sensors with a spatial and spectral resolution suitable for the characterization of urban surfaces are listed in Table 2.

Table 2. Main airborne commercial sensor suitable for the characterization of urban surfaces.

\begin{tabular}{|c|c|c|c|c|c|}
\hline Sensor & Revisit Period & Swath Width (km) & Band Name & $\begin{array}{c}\text { Spectral Range } \\
(\mathrm{nm})\end{array}$ & $\begin{array}{c}\text { Spatial } \\
\text { Resolution (m) }\end{array}$ \\
\hline \multirow{5}{*}{ IKONOS-2 } & \multirow{5}{*}{3 days } & \multirow{5}{*}{11.3} & Pan & $445-900$ & \multirow[t]{2}{*}{1} \\
\hline & & & Blue & $445-516$ & \\
\hline & & & Green & $505-595$ & \multirow[t]{3}{*}{3.2} \\
\hline & & & Red & $632-698$ & \\
\hline & & & Near-IR & $757-853$ & \\
\hline \multirow{5}{*}{ QuickBird } & \multirow{5}{*}{ 3-4 days } & \multirow{5}{*}{$14.9-16.8$} & Pan & $445-900$ & \multirow[t]{2}{*}{0.61} \\
\hline & & & Blue & $430-545$ & \\
\hline & & & Green & $466-620$ & \multirow{3}{*}{2.44} \\
\hline & & & Red & $590-710$ & \\
\hline & & & Near-IR & $715-918$ & \\
\hline \multirow{5}{*}{ Geoeye-1 } & \multirow{5}{*}{$2-3$ days } & \multirow{5}{*}{15} & Pan & $450-900$ & \multirow[t]{2}{*}{0.41} \\
\hline & & & Blue & $450-520$ & \\
\hline & & & Green & $520-600$ & \multirow{3}{*}{1.65} \\
\hline & & & Red & $620-690$ & \\
\hline & & & Near-IR & $760-900$ & \\
\hline \multirow{10}{*}{ World-View3 } & \multirow{10}{*}{$<1$ day } & \multirow{10}{*}{13.1} & Pan & $450-800$ & \multirow{9}{*}{1.24} \\
\hline & & & Coastal & $400-450$ & \\
\hline & & & Blue & $450-510$ & \\
\hline & & & Green & $510-580$ & \\
\hline & & & Yellow & $585-625$ & \\
\hline & & & Red & $630-690$ & \\
\hline & & & Red Edge & $705-745$ & \\
\hline & & & Near-IR1 & $770-895$ & \\
\hline & & & Near-IR2 & 860-1040 & \\
\hline & & & 8 SWIR bands & $1195-2365$ & 7.5 \\
\hline
\end{tabular}

The revisit period is an important parameter for satellite observations. It represents the time elapsed between acquisition of the same site on Earth by the satellite. It depends on the satellite's orbit, the site location, and the maximum swath width that can be viewed by the satellite sensor. Each satellite also features several sensors, covering different wavebands of the spectral range. The WV3 sensor is different from the other satellites thanks to its four additional bands in the visible-near infrared region, which are useful for varied purposes: the study of vegetation and water properties, but also for a more accurate classification of urban coverings. For this reason, in the present study a WV3 image was used for an exploratory comparison and correlation between albedo data measured on the ground and that from the satellite, aimed for substantiation of this this review.

For the calculation of land surface albedo from remote sensing images, the problem often encountered is the conversion between the solar reflectance acquired in the narrowband satellite data and the calculation of broadband albedo [82,83]. Different formulas are available for calculating the land surface albedo for numerous satellite and airborne sensors with an adequate number of bands [27,84]. A study performed in the cities of California [27] showed how to obtain the albedo of the roofs, starting from aerial images with a high spatial and low spectral resolution. Other studies in the scientific literature of 
the sector provide albedo calculation methods (and related validation) depending on the sensor $[83,85]$.

Focusing on satellite sensors with multiple wavebands, it is possible to compute the albedo $\rho_{\text {sol }}$ from the spectral reflectance in each waveband. It is necessary to integrate the hemispheric bidirectional reflectance distribution function, which can be really difficult. A general formulation is:

$$
\rho_{\text {sol }}(\Lambda)=\int_{\Delta \lambda} R(\theta, \varphi, 2 \pi, \Lambda) d \lambda
$$

where $\Lambda$ represents the spectral range over which the albedo is calculated. The integration endpoints are given with the considered band interval $(\Delta \lambda)$. The integrand function $R$ is the hemispherical bidirectional reflectance distribution function mentioned above. This depends on the solar zenith angle $\theta$, the azimuth angle $\varphi$ between the direction of illumination and that of observation, as well as on the considered direction; in this case, $2 \pi$ indicates that the entire celestial vault is taken into account [75]. This function can be very complex and its calculation time and resource can be consuming. In [86,87], a simpler and faster method for albedo calculation was proposed. The calculation was made simpler by introducing surface spectral reflectance values, i.e., the values obtained after performing atmospheric correction. The albedo $\rho_{\text {sol }}$ is thereafter estimated as:

$$
\rho_{\text {sol }}=\sum w_{\lambda} \rho_{\lambda}
$$

where $\rho_{\lambda}$ represents the surface spectral reflectance, and $w_{\lambda}$ is a weight coefficient calculated from the ratio between the spectral solar irradiance $I_{\lambda}$ in each measurement band and the sum of the irradiances of all wavebands, that is:

$$
w_{\lambda} \approx \frac{I_{\lambda}}{\sum I_{\lambda}}
$$

$I_{\lambda}$ can be obtained from literature data, depending on the sensor type and its similarities (sensors with comparable spectral amplitude bands) $[27,85,88]$. Following an approach derived from Equation (1) and closer to the one used in the ASTM E903 standard test method [35] and its modifications, the weight coefficient $w_{\lambda}$ can also be calculated from the irradiance $I_{\lambda}$ in the considered waveband and the waveband width $\Delta \lambda$ :

$$
w_{\lambda}=\frac{I_{\lambda} \Delta \lambda}{\sum I_{\lambda} \Delta \lambda}
$$

\section{Exploratory Comparison of Field and Satellite Measurements}

\subsection{Test Area and Ground Measurement}

Five different built-up surfaces were selected as a preliminary experiment to test the matching between field and satellite measurements of solar reflectance. Four surfaces are located within the Engineering Campus and all of them are in the southern area of Modena city (Figure 4). They were installed before March 2016, when the used satellite images were recorded, and are characterized by very different colors (Table 3). Sites labelled MO28 and MO52 represent surfaces with both dark and white factory-applied coatings; in MO26, a black bitumen roof covered with basalt granules is present. The parking lot has a typical dark asphalt mantle. The residential building shows a steep-slope clay tile roof. The tiles are unglazed and without any finishing, so they have a homogeneous surface. 


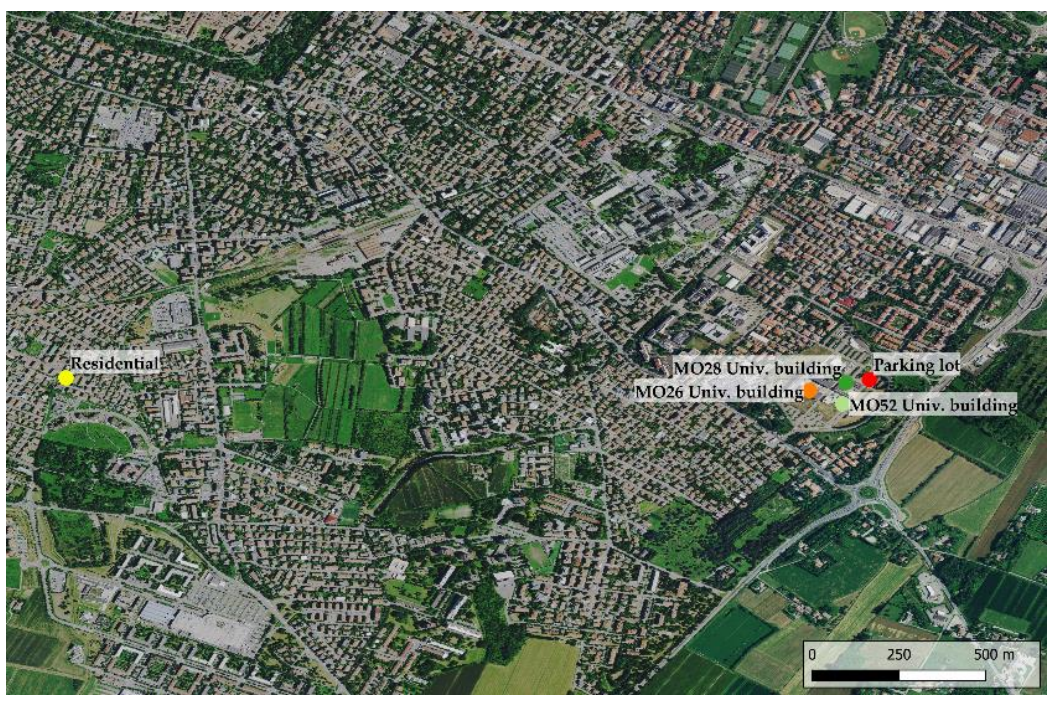

Figure 4. Analyzed surfaces in the south area of Modena.

Table 3. Analyzed surfaces and color codes for the spots on the map in Figure 4.

\begin{tabular}{ccc}
\hline Label & Type of Roof & Color Code on the Map \\
\hline MO26 Univ. building & Bitumen & Orange \\
MO28 Univ. building & Factory-applied coating & Dark green \\
MO52 Univ. building & Factory-applied coating & Light green \\
Parking lot & Asphalt & Red \\
Residential & Clay roof tile & Yellow \\
\hline
\end{tabular}

On each surface, at least 10 different ground measurements of solar reflectance were performed according to ASTM C1549 [44] with a solar spectrum reflectometer (SSR) v. 6.0 made by Devices and Services [56]. This instrument allows the measuring of the solar reflectance of flat opaque materials in the laboratory or, if equipped with a battery or an extension cord, in the field. The diffuse light source is a tungsten halogen lamp that illuminates the interior of the instrument head, which is coated with highly reflective $\mathrm{BaSO}_{4}$. The sample port must be placed against the tested surface. Four detectors covered with spectrally selective light filters (IR, Red, Blue and UV) record the reflected light through a collimating tube angled $10^{\circ}$ from the surface normal. After the calibration process, the reference spectrum is selected between those specified in ASTM E891 [38], ASTM G173 [39], AM1GH, etc. In this study, the air mass 1.5 beam normal spectrum from ASTM E891 and the air mass 1 global horizontal spectrum (AM1GH) are considered.

\subsection{Satellite Measurements}

WorldView 3 hosts a multispectral sensor with a relatively high spatial resolution. This satellite system can provide, with a short revisit time of about four days, images with five wavebands in the visible spectral range (coastal, blue, green, yellow, red), three wavebands in the near infrared range (red edge, NIR1, NIR2) and eight wavebands in the short-wave infrared range (SWIR). The spatial resolution of the sensor is $0.31 \mathrm{~m}$ in the panchromatic channel, $1.24 \mathrm{~m}$ in the multispectral channel, $3.70 \mathrm{~m}$ in the SWIR channel (supplied to the customer at $7.5 \mathrm{~m}$ ) and $30 \mathrm{~m}$ in the CAVIS (clouds, aerosols, vapors, ice and snow) channels.

For this study, a satellite image of about $28.3 \mathrm{~km}^{2}$, covering most of the residential area of Modena and its surroundings, was used for comparison with the ground-acquired data. The image (Figure 5) was acquired on 15 March 2016 by the WV3 sensor hosted on the WorldView 3 satellite platform. Specifically, an archive image was acquired consisting of the 8 bands in the Vis-NIR (resampled at $2 \mathrm{~m}$ ) and the panchromatic band (resampled at 
$0.5 \mathrm{~m}$ ). It was not possible to use data in the SWIR channel, where eight additional bands would be available in principle, due to the low spatial resolution.

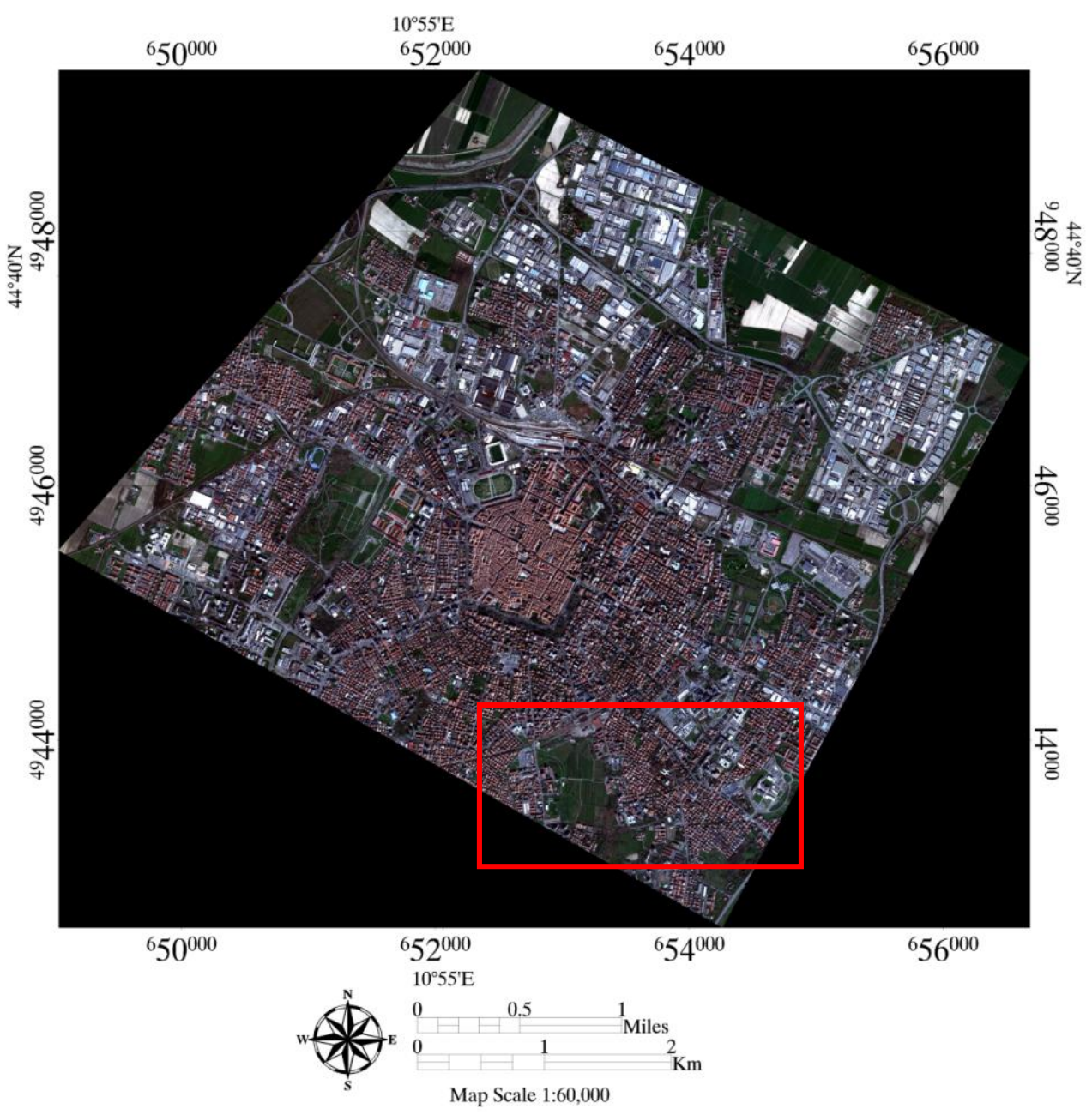

Figure 5. WV3 satellite image and area of investigation (red boxed).

Details on the spectral features of the sensor wavebands (obtained from the image metadata) are shown in Table 4 . The chosen bands are characterized by narrow spectral response paths, close to the ideal case of a square wave. Other data reported in Table 4 include the calibration parameters useful for obtaining the TOA (top of atmosphere) radiance, starting from the raw digital number data provided by the sensor manufacturer. The methodology used for the image elaboration and some useful information about the sensor were obtained from [89]. The image was first pre-processed with radiometric and atmospheric correction to obtain the BOA (bottom of the atmosphere) reflectance. An area of interest $(\mathrm{AOI})$ of $3 \times 3$ pixels (about $3.7 \times 3.7 \mathrm{~m}$ ) was extracted from the image for each type of analyzed surface. We selected two AOI for both the sites MO28 and MO52 covered with dark and white factory-applied coatings, one AOI for MO26 (black bitumen roof covered with basalt granules), one AOI for the parking lot, and one AOI for the residential building. 
Table 4. Spectral bands [89].

\begin{tabular}{cccccc}
\hline Sensor & $\begin{array}{c}\text { Center } \\
\text { Wavelength } \\
(\mathbf{n m})\end{array}$ & $\begin{array}{c}\text { Effective } \\
\text { Bandwidth } \\
(\boldsymbol{\mu m})\end{array}$ & GAIN & OFFSET & $\begin{array}{c}\text { Abscalfactor } \\
(\boldsymbol{\mu m})\end{array}$ \\
\hline Panchromatic & 649.4 & 0.2896 & 0.923 & -1.700 & 0.039426 \\
Coastal Blue & 427.4 & 0.0405 & 0.863 & -7.154 & 0.014329 \\
Blue & 481.9 & 0.0540 & 0.905 & -4.189 & 0.011608 \\
Green & 547.1 & 0.0618 & 0.907 & -3.287 & 0.008857 \\
Yellow & 604.3 & 0.0381 & 0.938 & -1.816 & 0.006843 \\
Red & 660.1 & 0.0585 & 0.945 & -1.350 & 0.010200 \\
Red edge & 722.7 & 0.0387 & 0.980 & -2.617 & 0.006220 \\
Near-IR1 & 824.0 & 0.1004 & 0.982 & -3.752 & 0.011797 \\
Near-IR2 & 913.6 & 0.0889 & 0.954 & -1.507 & 0.010638 \\
\hline
\end{tabular}

The reflectance trends in the eight WV3 bands considered (coastal, blue, green, yellow, red, red edge, NIR1, NIR2) for each surface type are shown in Figure 6.
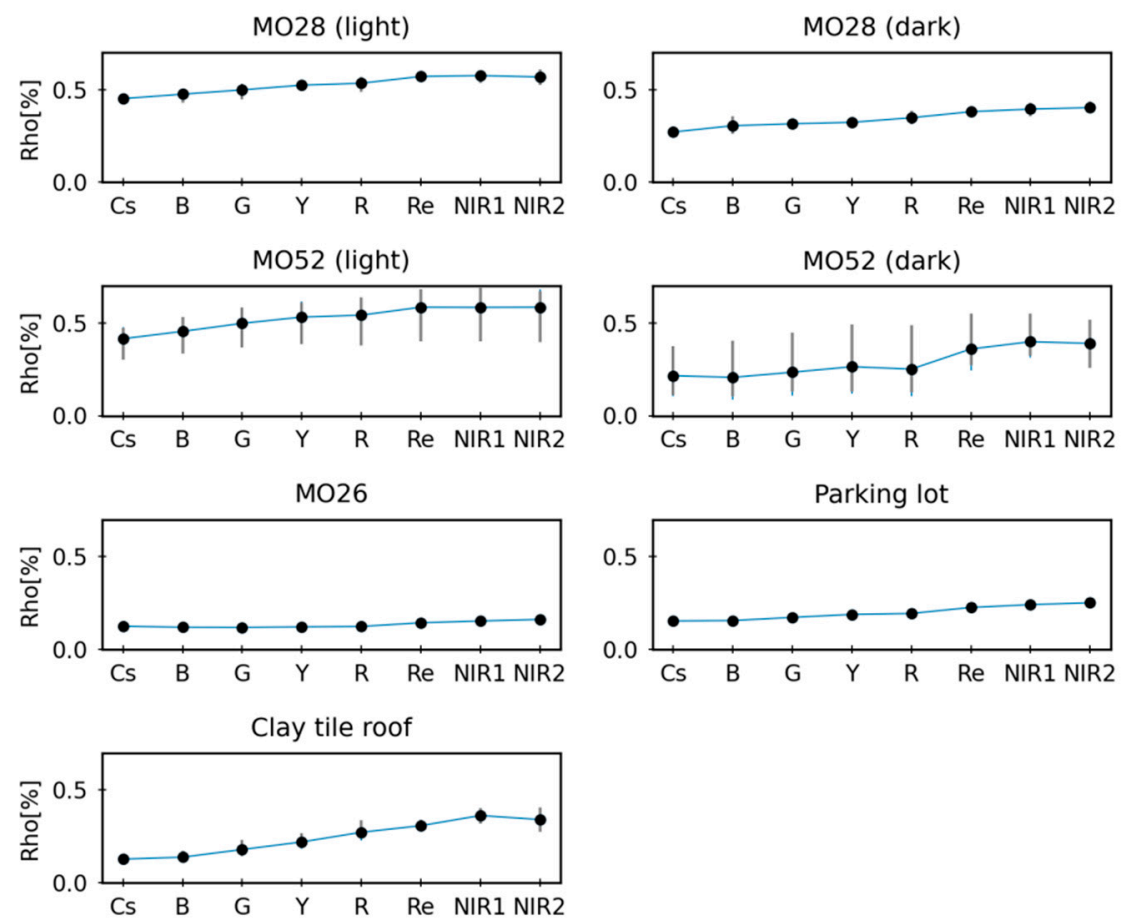

Figure 6. Spectral signature computed for each AOIs.

Figure 6 shows similar spectral signatures for the white factory-applied coatings and rougher signatures for the dark coatings of MO28 and MO52. Both AOIs of MO52 showed dispersed values of reflectance (see the error bars), probably related to surface non-homogeneity (due to the aging or dusts) or shadows (image acquired with non-nadir sensor).

The method suggested in [86,87] was used to calculate the albedo, starting from the spectral irradiance coefficients for each band. The weight coefficients were then calculated according to the formulas in Equations (6) and (7). The spectral irradiance data and the weight coefficients are reported in Table 5. 
Table 5. Satellite sensors and weight coefficients matching selected solar spectra.

\begin{tabular}{|c|c|c|c|c|c|c|}
\hline \multirow{2}{*}{ Sensor } & \multirow{2}{*}{$\begin{array}{c}\text { Reference Irradiance } \\
\left(\mathrm{W} /\left(\mathrm{m}^{2} \mu \mathrm{m}\right)\right)\end{array}$} & \multicolumn{2}{|c|}{ Sensor Wavebands (nm) } & \multicolumn{3}{|c|}{ Weight Coefficients } \\
\hline & & from & to & Thuilier [89] & AM1GH [45] & E891BN [38] \\
\hline Coastal Blue & 1757.89 & 400 & 450 & 0.145 & 0.095 & 0.067 \\
\hline Blue & 2004.61 & 450 & 510 & 0.166 & 0.157 & 0.128 \\
\hline Green & 1830.18 & 510 & 580 & 0.151 & 0.166 & 0.156 \\
\hline Yellow & 1712.07 & 585 & 625 & 0.141 & 0.100 & 0.101 \\
\hline Red & 1535.33 & 630 & 690 & 0.127 & 0.136 & 0.143 \\
\hline Red edge & 1348.08 & 705 & 745 & 0.111 & 0.103 & 0.116 \\
\hline Near-IR1 & 1055.94 & 770 & 895 & 0.087 & 0.162 & 0.193 \\
\hline Near-IR2 & 858.77 & 860 & 1040 & 0.071 & 0.081 & 0.096 \\
\hline
\end{tabular}

The chosen irradiance values used in Equation (6) are those of Thuilier, as suggested in [89], because they are currently used by the WV3 sensor manufacturer for calibration tasks. Alternative sets of weight coefficients were also calculated by Equation (7), obtained from reference spectra such as the air mass 1.5 beam normal spectrum from ASTM E891 (labelled E891BN) [38] and the air mass 1 global horizontal (AM1GH) spectrum [45], using the effective center wavelength and bandwidth reported in Table 5. In this regard, the wavebands of the satellite sensors are not continuous and, above all, do not cover the whole range of solar radiation; therefore, the reflectance in the uncovered wavebands has been approximated with that measured by the closest sensors, and their associated weight coefficients have been increased accordingly.

A comparison of ground and remote measurements (Table 6 and Figure 7) shows that the solar reflectance measured from satellite data is in good agreement with that measured in-field by the solar spectrum reflectometer. Satellite measurements weighted with irradiance data from ASTM E891 slightly overestimate those weighted with irradiance data from AM1GH and Thuilier [89], due to the higher near-infrared spectral content. Above all, ground measurements are more often overestimated by remote measurement rather than underestimated, probably because satellite images were acquired years before ground measurements, and ageing of the tested surface may have occurred in the meantime. Moreover, efforts are certainly needed to obtain a proper matching between remote measurement and ground or laboratory measurements used for solar reflectance rating in terms of choice of the weighting coefficient.

Table 6. Ground and satellite solar reflectance measurements with different reference spectra.

\begin{tabular}{cccccc}
\hline & \multicolumn{2}{c}{ Ground Measurements } & \multicolumn{3}{c}{ Satellite Measurements } \\
\cline { 2 - 5 } & AM1GH & E891BN & Thuilier [89] & AM1GH & E891BN \\
\hline MO52 (light) & 0.527 & 0.551 & 0.513 & 0.523 & 0.532 \\
MO52 (dark) & 0.247 & 0.267 & 0.273 & 0.286 & 0.296 \\
MO26 & 0.104 & 0.101 & 0.128 & 0.131 & 0.133 \\
MO28 (light) & 0.545 & 0.569 & 0.515 & 0.523 & 0.530 \\
MO28 (dark) & 0.279 & 0.311 & 0.333 & 0.341 & 0.348 \\
Parking lot & 0.187 & 0.198 & 0.188 & 0.195 & 0.200 \\
Clay tile roof & 0.266 & 0.305 & 0.224 & 0.240 & 0.253 \\
\hline
\end{tabular}



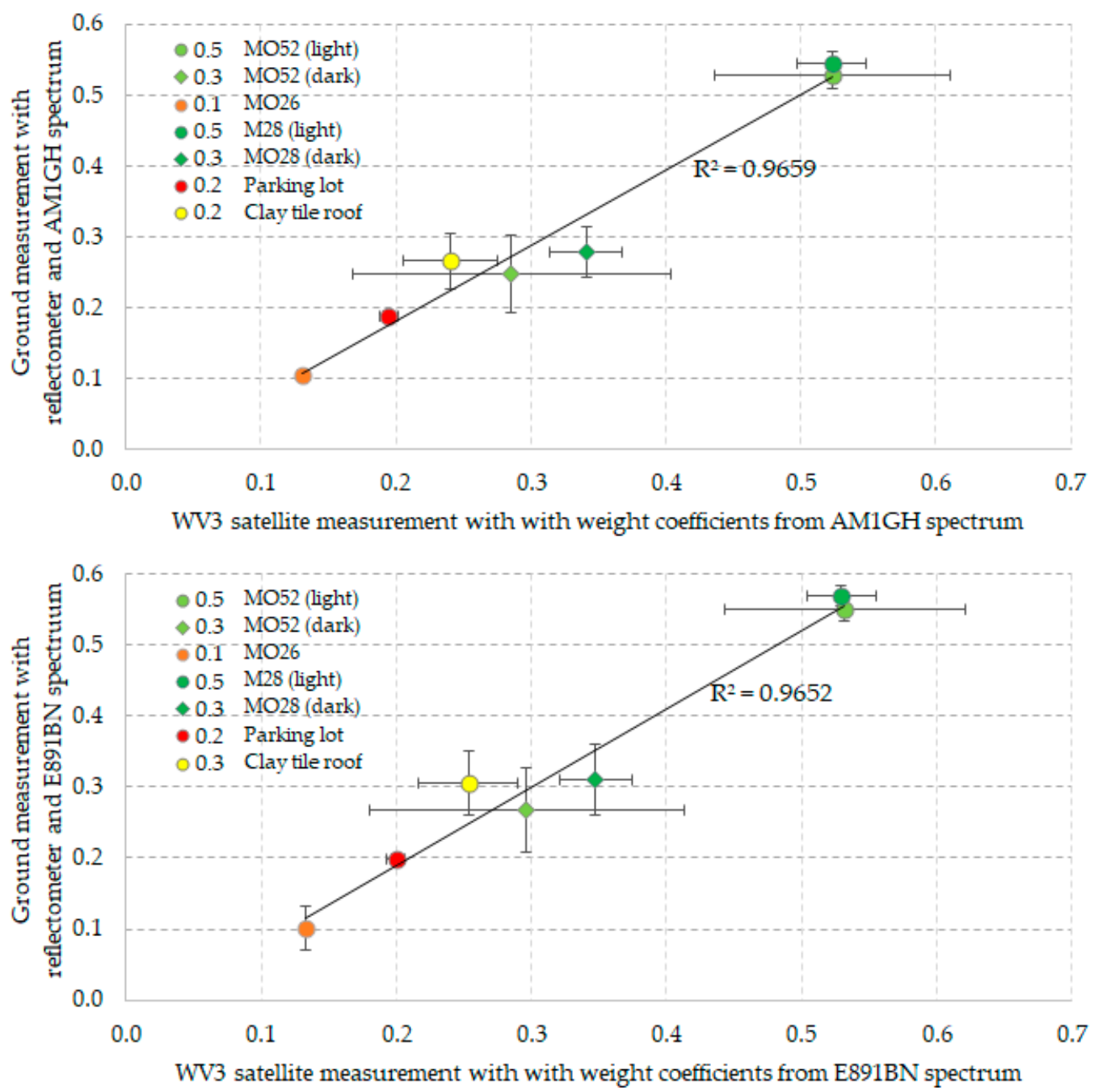

Figure 7. Comparison between ground and satellite solar reflectance measurement with E891BN and AM1GH reference spectra.

WV3 sensors do not cover the ultra-violent range between 300 and $400 \mathrm{~nm}$; however, little solar energy falls in that range. Much more energy falls in the short-wave near infrared range (SWIR) between 1000 and $2500 \mathrm{~nm}$, where the WV3 features 8 different sensors, but with a spatial resolution above $3.7-7.5 \mathrm{~m}$, which is not enough to clearly identify and characterize most urban surfaces. To the authors' best knowledge, commercial satellites with sensors covering the SWIR range and providing adequate spatial resolution are not available, nor are they expected to be launched in the upcoming years.

The outcomes of the present study suggest that WV3 and analogous platforms can be useful in monitoring the ageing of built-up surfaces and in providing information to their manufacturers. Agreement with ground measurements can be improved by properly weighting the signal from the different satellite sensors according to the reference solar spectrum, as well as by using data acquired simultaneously. However, satellite measurements are probably not adequate for performance rating due to their incomplete coverage of the solar range, from 300 to $2500 \mathrm{~nm}$, with adequate spatial resolution in all wavebands. On the other hand, in recent years, a progressive spread of the use of drones as remote observation tools has been observed. These platforms are economically accessible and allow for low-altitude flights $(10-100 \mathrm{~m})$, from which digital terrain models and orthophotos with high geometric resolutions can be obtained, in the order of centimeters. At the moment, commercial drones mainly carry RGB cameras, which do not provide multispectral data, but only images with high spatial resolution. Nonetheless, drones with 
multispectral and hyperspectral cameras are also being introduced. For example, they are used for studies on precision agriculture [90,91], vegetation [92,93] or water [94,95]. Drones equipped with cameras covering the whole solar range could represent a useful tool for the characterization and even the rating of solar reflectance of urban surfaces. Compared to satellite images, there could be an advantage in terms-if not in image cost, at least in spatial and spectral resolution. The disadvantage would be that the measurement site must be directly accessed and flown over, and only a relatively small area can be characterized in a single test session.

\section{Concluding Remarks}

Rating programs for solar reflective materials have converged on the use of spectrophotometers according to ASTM E903, or solar spectrum reflectometers based on ASTM C1549. For variegated, textured or profiled surfaces, a pyranometer can also be used according to ASTM E1918. Spectrophotometers and reflectometers return very similar results, provided that the same solar spectrum is considered to weight spectral or waveband measurements. Using spectra different from those commonly used in rating programs, i.e., air mass 1.5 beam normal from ASTM E891, may yield a non-negligible discrepancy on the measured solar reflectance. The same may occur with pyranometers, which use the solar spectrum of the site and time of the test. For product rating, the solar spectrum from ASTM E891 is generally mandatory, even if it does not perfectly match the solar spectrum relevant to building energy.

While the measurement procedure is relatively simple, especially with the reflectometer, testing of a large number of samples is long and laborious. Moreover, in situ measurement on roofs may be difficult and time consuming. On the other hand, advancements of satellite systems have made available multi-spectral images with reasonable spatial resolution. Large areas can thus be tested with relative ease, and time-sequences of images can be exploited to analyze the ageing process of solar reflective materials. Satellite images are also more affordable than airborne images. To obtain adequate matching with ground or laboratory measurements, satellite data must be properly manipulated in terms of weighting of measurements on different sensors/wavebands. However, available satellites do not cover the whole range of interest for solar radiation with adequate spatial resolution-at least not for performance rating. Nonetheless, the quality of measurement that can be achieved seems adequate to support product development focused on the ageing of built surfaces, as well as to provide data for policy development or even to broadly check the compliance of roof and pavement surfaces with mandatory requirements.

Author Contributions: Conceptualization, A.M. and C.F.; methodology, S.C. and F.D.; software, S.C. and F.D.; validation, C.F.; formal analysis, S.C., C.F. and F.D.; investigation, S.C., C.F. and F.D.; resources, A.M.; data curation, S.C.; writing-original draft preparation, S.C., C.F. and F.D.; writing-review and editing, A.M.; visualization, S.C.; supervision, A.M.; project administration, A.M.; funding acquisition, A.M. All authors have read and agreed to the published version of the manuscript.

Funding: This research received no external funding.

Conflicts of Interest: The authors declare no conflict of interest. 


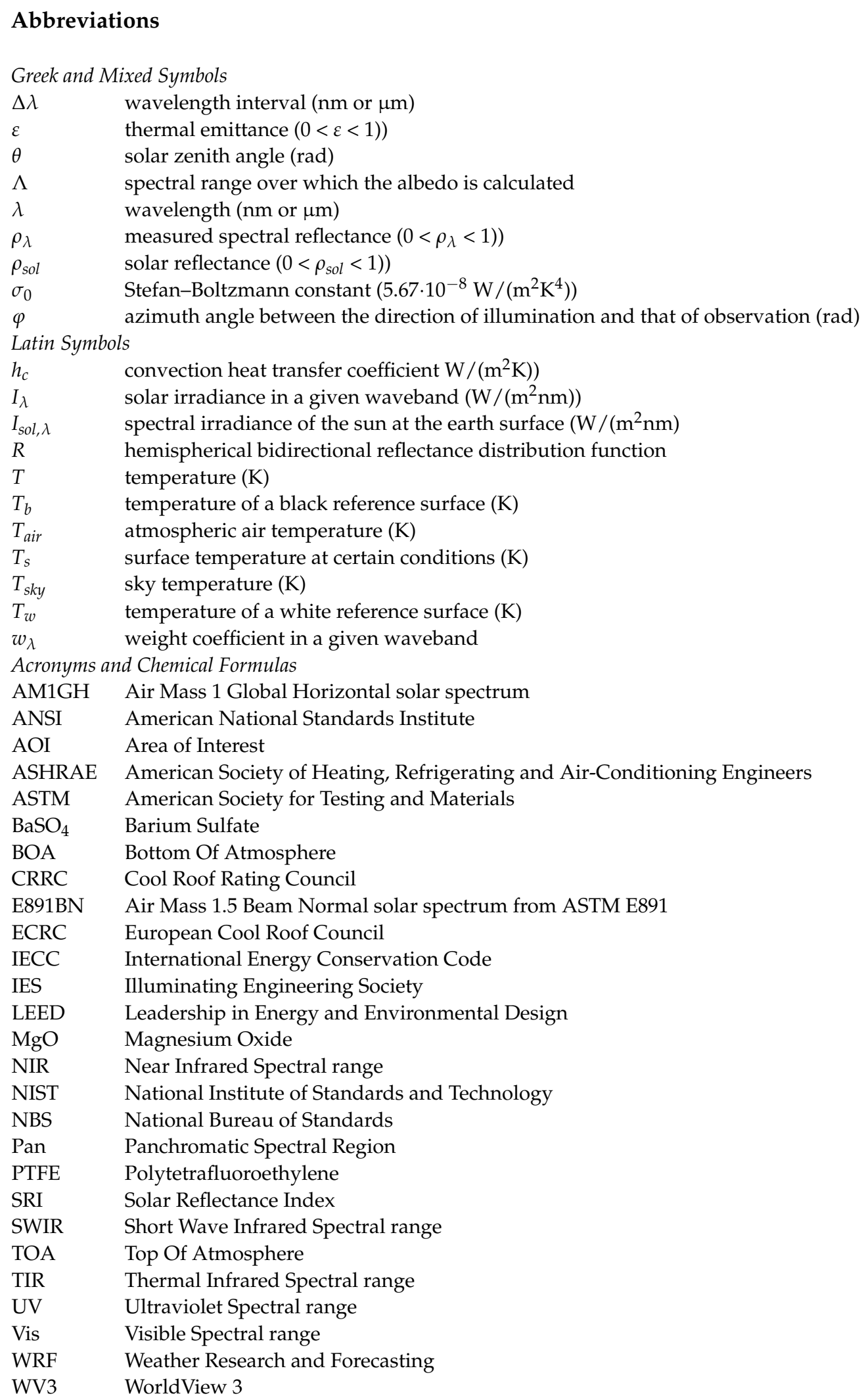




\section{References}

1. Akbari, H.; Pomerantz, M.; Taha, H. Cool surfaces and shade trees to reduce energy use and improve air quality in urban areas. Sol. Energy 2001, 70, 295-310. [CrossRef]

2. Akbari, H.; Cartalis, C.; Kolokotsa, D.; Muscio, A.; Pisello, A.L.; Rossi, F.; Santamouris, M.; Synnefa, A.; Wong, N.H.; Zinzi, M. Local climate change and urban heat island mitigation techniques-The state of the art. J. Civ. Eng. Manag. 2016, 22, 1-16. [CrossRef]

3. Synnefa, A.; Santamouris, M.; Akbari, H. Estimating the effect of using cool coatings on energy loads and thermal comfort in residential buildings in various climatic conditions. Energy Build. 2007, 39, 1167-1174. [CrossRef]

4. Levinson, R.; Berdahl, P.; Akbari, H. Solar spectral optical properties of pigments-Part II: Survey of common colorants. Sol. Energy Mat. Sol. Cells 2005, 89, 351-389. [CrossRef]

5. Synnefa, A.; Santamouris, M.; Apostolakis, K. On the development, optical properties and thermal performance of cool colored coatings for the urban environment. Sol. Energy 2007, 81, 488-497. [CrossRef]

6. Santamouris, M. Using cool pavements as a mitigation strategy to fight urban heat island-A review of the actual developments. Renew. Sustain. Energy Rev. 2013, 26, 224-240. [CrossRef]

7. Santamouris, M.; Synnefa, A.; Karlessi, T. Using advanced cool materials in the urban built environment to mitigate heat islands and improve thermal comfort conditions. Sol. Energy 2011, 85, 3085-3102. [CrossRef]

8. Pisello, A.L. State of the art on the development of cool coatings for buildings and cities. Sol. Energy 2017, 144, 660-680. [CrossRef]

9. Rossi, F.; Castellani, B.; Presciutti, A.; Morini, E.; Anderini, E.; Filipponi, M.; Nicolini, A. Experimental evaluation of urban heat island mitigation potential of retro-reflective pavement in urban canyons. Energy Build. 2016, 126, 340-352. [CrossRef]

10. Levinson, R.; Chen, S.; Slack, J.; Goudey, H.; Harima, T.; Berdahl, P. Design, characterization, and fabrication of solar-retroreflective cool-wall materials. Sol. Energy Mat. Sol. Cells 2020, 206, 110117. [CrossRef]

11. Karlessi, T.; Santamouris, M.; Apostolakis, K.; Synnefa, A.; Livada, I. Development and testing of thermochromic coatings for buildings and urban structures. Sol. Energy 2009, 83, 538-551. [CrossRef]

12. Garshasbi, S.; Huang, S.; Valenta, J.; Santamouris, M. Can quantum dots help to mitigate urban overheating? An experimental and modelling study. Sol. Energy 2020, 206, 308-316. [CrossRef]

13. ASTM E1980-11 (Reapproved 2019), Standard Practice for Calculating Solar Reflectance Index of Horizontal and Low-Sloped Opaque Surfaces; ASTM International: West Conshohocken, PA, USA, 2019.

14. Muscio, A. The Solar Reflectance Index as a Tool to Forecast the Heat Released to the Urban Environment: Potentiality and Assessment Issues. Climate 2018, 6, 12. [CrossRef]

15. Cool Roof Rating Council. Product Rating Program Manual CRRC-1; Cool Roof Rating Council: Portland, OR, USA, 2021. Available online: https: / / coolroofs.org (accessed on 1 August 2021).

16. Cool Roof Rating Council. ANSI/CRRC S100 (2021)—Standard Test Methods for Determining Radiative Properties of Materials; Cool Roof Rating Council: Portland, OR, USA, 2021. Available online: https: / / coolroofs.org (accessed on 1 August 2021).

17. European Cool Roof Council. Product Rating Program; European Cool Roof Council: Brussels, Belgium, 2020. Available online: https: / / coolroofcouncil.eu (accessed on 1 August 2021).

18. California Energy Commission. 2019 Building Energy Efficiency Standards-Title 24; California Energy Commission: Sacramento, CA, USA, 2019. Available online: www.energy.ca.gov/title24 (accessed on 1 August 2021).

19. International Code Council. 2021 International Energy Conservation Code; International Code Council: Washington, DC, USA, 2021. Available online: https:/ / codes.iccsafe.org (accessed on 1 August 2021).

20. ASHRAE. ANSI/ASHRAE/IES Standard 90.1-2019-Energy Standard for Buildings Except Low-Rise Residential Buildings; ASHRAE: Atlanta, GA, USA, 2019. Available online: https://www.ashrae.org/technical-resources/bookstore/standard-90-1 (accessed on 1 August 2021).

21. U.S. Green Building Council. LEED v4.1; U.S. Green Building Council: Washington, DC, USA, 2021. Available online: www. usgbc.org/leed (accessed on 1 August 2021).

22. Ge, J.; Levinson, R. The Advancement of Cool Roof Standards in China from 2010 to 2015; LBNL-1007007; Lawrence Berkeley National Laboratory, University of California: Berkeley, CA, USA, 2016.

23. Berdahl, P.; Akbari, H.; Levinson, R.; Miller, W.A. Weathering of roofing materials-An overview. Constr. Build. Mat. 2008, 22, 423-433. [CrossRef]

24. Sleiman, M.; Kirchstetter, T.W.; Berdahl, P.; Gilbert, H.E.; Quelen, S.; Marlot, L.; Preble, C.V.; Chen, S.; Montalbano, A.; Rosseler, O.; et al. Soiling of building envelope surfaces and its effect on solar reflectance-Part II: Development of an accelerated aging method for roofing materials. Sol. Energy Mater. Sol. Cells 2014, 122, 271-281. [CrossRef]

25. ASTM D7897-18 - Standard Practice for Laboratory Soiling and Weathering of Roofing Materials to Simulate Effects of Natural Exposure on Solar Reflectance and Thermal Emittance; ASTM International: West Conshohocken, PA, USA, 2018.

26. Paolini, R.; Terraneo, G.; Ferrari, C.; Sleiman, M.; Muscio, A.; Metrangolo, P.; Poli, T.; Destaillats, H.; Zinzi, M.; Levinson, R. Effects of soiling and weathering on the albedo of building envelope materials: Lessons learned from natural exposure in two European cities and tuning of a laboratory simulation practice. Sol. Energy Mat. Sol. Cells 2020, 205, 110264. [CrossRef]

27. Ban-Weiss, G.A.; Woods, J.; Levinson, R. Using remote sensing to quantify albedo of roofs in seven California cities, Part 1: Methods. Sol. Energy 2015, 115, 777-790. [CrossRef] 
28. Heiden, U.; Heldens, W.; Roessner, S.; Segl, K.; Esch, T.; Mueller, A. Urban structure type characterization using hyperspectral remote sensing and height information. Landsc. Urban Plan. 2012, 105, 361-375. [CrossRef]

29. Despini, F.; Ferrari, C.; Bigi, A.; Libbra, A.; Teggi, S.; Muscio, A.; Ghermandi, G. Correlation between remote sensing data and ground based measurements for solar reflectance retrieving. Energy Build. 2016, 114, 227-233. [CrossRef]

30. Ban-Weiss, G.A.; Woods, J.; Millstein, D.; Levinson, R. Using remote sensing to quantify albedo of roofs in seven California cities, Part 2: Results and application to climate modeling. Sol. Energy 2015, 115, 791-805. [CrossRef]

31. Franch, B.; Vermote, E.F.; Claverie, M. Intercomparison of Landsat albedo retrieval techniques and evaluation against in situ measurements across the US SURFRAD network. Remote Sens. Environ. 2014, 152, 627-637. [CrossRef]

32. Despini, F.; Ferrari, C.; Santunione, G.; Tommasone, S.; Muscio, A.; Teggi, S. Urban surfaces analysis with remote sensing data for the evaluation of UHI mitigation scenarios. Urban Clim. 2021, 35, 100761. [CrossRef]

33. Modest, M. Radiative Heat Transfer; Academic Press: New York, NY, USA, 2013; p. 76.

34. Labsphere Inc. Optical-Grade Spectralon Reflectance Material (Spectralon Datasheet); Labsphere Inc.: Sutton, NH, USA, 2019. Available online: https://www.labsphere.com/site/assets/files/1827/pb-13021-000_rev_03_og_spectralon-1.pdf (accessed on 27 August 2021).

35. ASTM E903-20, Standard Test Method for Solar Absorptance, Reflectance, and Transmittance of Materials Using Integrating Spheres; ASTM International: West Conshohocken, PA, USA, 2020.

36. ASTM E772-15-Standard Terminology of Solar Energy Conversion; ASTM International: West Conshohocken, PA, USA, 2015.

37. Lind, M.A.; Pettit, R.B.; Masterson, K.D. The sensitivity of solar transmittance, reflectance and absorptance to selected averaging procedures and solar irradiance distribution. Trans. ASME J. Sol. Energy Eng. 1960, 102, 34-40. [CrossRef]

38. ASTM E891-87 (Reapproved 1992)_Tables for Terrestrial Direct Normal Solar Spectral Irradiance Tables for Air Mass 1.5 (Withdrawn 1999); ASTM International: West Conshohocken, PA, USA, 1992.

39. ASTM G173-03 (Reapproved 2020)—Standard Tables for Reference Solar Spectral Irradiances: Direct Normal and Hemispherical on Tilted Surface; ASTM International: West Conshohocken, PA, USA, 2020.

40. Levinson, R.; Akbari, H.; Berdahl, P. Measuring solar reflectance-Part I: Defining a metric that accurately predicts solar heat gain. Sol. Energy 2010, 84, 1717-1744. [CrossRef]

41. Levinson, R.; Akbari, H.; Berdahl, P. Measuring solar reflectance-Part II: Review of practical methods. Sol. Energy 2010, 84, 1745-1759. [CrossRef]

42. EN 410:2011—Glass in Building—Determination of Luminous and Solar Characteristics of Glazing; European Committee for Standardization (CEN): Brussels, Belgium, 2011.

43. Ferrari, C.; Libbra, A.; Muscio, A.; Cristina Siligardi, C. Influence of the irradiance spectrum on solar reflectance measurements. Adv. Build. Energy Res. 2013, 7, 244-253. [CrossRef]

44. ASTM C1549-16-Standard Test Method for Determination of Solar Reflectance Near Ambient Temperature Using a Portable Solar Reflectometer; ASTM International: West Conshohocken, PA, USA, 2016.

45. NREL-National Renewable Energy Laboratory. SMARTS: Simple Model of the Atmospheric Radiative Transfer of Sunshine. Available online: https:/ / www.nrel.gov/grid/solar-resource/smarts.html (accessed on 1 August 2021).

46. Petrie, T.W.; Desjarlais, A.O.; Robertson, R.H.; Parker, D.S. Comparison of techniques for in situ nondamaging measurement of solar reflectances of low-slope roof membranes. Int. J. Thermophys. 2001, 22, 1613-1628. [CrossRef]

47. Devices \& Services, Co. DES Technical Note 82-1-Solar Spectrum Reflectometer Updates and Design Modifications; Devices \& Services Co.: Dallas, TX, USA, 1981. Available online: https://www.devicesandservices.com/TechNotes/TN82-1.pdf (accessed on 1 August 2021).

48. Devices \& Services, Co. DES Technical Note 79-16-The Solar Spectrum Reflectometer; Devices \& Services Co.: Dallas, TX, USA, 1979. Available online: https:/ / www.devicesandservices.com/TechNotes/TN79-16.pdf (accessed on 1 August 2021).

49. Levinson, R.; Chen, S.; Berdahl, P.; Rosado, P.; Medina, L.A. Reflectometer measurement of roofing aggregate albedo. Sol. Energy 2014, 100, 159-171. [CrossRef]

50. Hooshangi, H.R.; Akbari, H.; Touchaei, A.G. Measuring solar reflectance of variegated flat roofing materials using quasi-Monte Carlo method. Energy Build. 2016, 114, 234-240. [CrossRef]

51. Devices \& Services, Co. DES Technical Note 08-1-Model SSR-ER-Solar Reflectance Measurements of Irregular Surfaces; Devices \& Services Co.: Dallas, TX, USA, 2008. Available online: https://www.devicesandservices.com/TechNotes/TN08-1.pdf (accessed on 1 August 2021).

52. Devices \& Services, Co. DES Technical Note 09-2-A Proposed Correction to Reflectance Measurements of Profiled Surfaces; Devices \& Services Co.: Dallas, TX, USA, 2009. Available online: https://www.devicesandservices.com/TechNotes/TN09-2.pdf (accessed on 1 August 2021).

53. Levinson, R.; Egolf, M.; Chen, S.; Berdahl, P. Experimental comparison of pyranometer, reflectometer, and spectrophotometer methods for the measurement of roofing product albedo. Sol. Energy 2020, 206, 826-847. [CrossRef]

54. Devices \& Services, Co. DES Technical Note 11-1-SSR-ER Reflectance Measurements for Large Radius Cylindrical Surfaces; Devices \& Services Co.: Dallas, TX, USA, 2011. Available online: https://www.devicesandservices.com/TechNotes/TN11-1.pdf (accessed on 1 August 2021). 
55. Devices \& Services, Co. Solar Spectrum Reflectometer Model SSR-ER Version 6-Specifications Sheet; Devices \& Services Co.: Dallas, TX, USA, 2021. Available online: https://www.devicesandservices.com/SSR\%20Version\%206\%20Spec\%20Sheet.pdf (accessed on 1 August 2021).

56. Devices \& Services, Co. DES Technical Note 09-1-Solar Spectrum Reflectometer Version 6.0; Devices \& Services Co.: Dallas, TX, USA, 2009. Available online: https://www.devicesandservices.com/TechNotes/TN09-1.pdf (accessed on 1 August 2021).

57. ASTM E1918-16-Standard Test Method for Measuring Solar Reflectance of Horizontal and Low-Sloped Surfaces in the Field; ASTM International: West Conshohocken, PA, USA, 2016.

58. Akbari, H.; Levinson, L.; Stern, S. Procedure for measuring the solar reflectance of flat or curved roofing assemblies. Sol. Energy 2008, 82, 648-655. [CrossRef]

59. Qin, Y.; He, H. A new simplified method for measuring the albedo of limited extent targets. Sol. Energy 2017, 157, 1047-1055. [CrossRef]

60. Akbari, H.; Touchaei, A.G. Modeling and labeling heterogeneous directional reflective roofing materials. Sol. Energy Mat. Sol. Cells 2014, 124, 192-210. [CrossRef]

61. Yuan, J.; Emura, K.; Farnham, C. A method to measure retro-reflectance and durability of retro-reflective materials for building outer walls. J. Build. Phys. 2015, 38, 500-516. [CrossRef]

62. Yuan, J.; Farnham, C.; Emura, K. A study on the accuracy of determining the retroreflectance of retro-reflective material by heat balance. Sol. Energy 2015, 122, 419-428. [CrossRef]

63. Yuan, J.; Emura, K.; Farnham, C.; Sakai, H. Application of glass beads as retro-reflective facades for urban heat island mitigation: Experimental investigation and simulation analysis. Build. Environ. 2016, 105, 140-152. [CrossRef]

64. Yuan, J.; Emura, K.; Sakai, H.; Farnham, C.; Lu, S. Optical analysis of glass bead retroreflective materials for urban heat island mitigation. Sol. Energy 2016, 132, 203-213. [CrossRef]

65. Harima, T.; Nagahama, T. Evaluation methods for retroreflectors and quantitative analysis of near-infrared upward reflective solar control window film-Part I: Theory. Sol. Energy 2017, 148, 177-192. [CrossRef]

66. Harima, T.; Nagahama, T. Evaluation methods for retroreflectors and quantitative analysis of near-infrared upward reflective solar control window film_Part II: Optical properties evaluation and verification results. Sol. Energy 2017, 148, 164-176. [CrossRef]

67. Rossi, F.; Pisello, A.L.; Nicolini, A.; Filipponi, M.; Palombo, M. Analysis of retro-reflective surfaces for urban heat island mitigation: A new analytical model. Appl. Energy 2014, 114, 621-631. [CrossRef]

68. Rossi, F.; Castellani, B.; Presciutti, A.; Morini, E.; Filipponi, M.; Nicolini, A.; Santamouris, M. Retroreflective façades for urban heat island mitigation: Experimental investigation and energy evaluations. Appl. Energy 2015, 145, 8-20. [CrossRef]

69. Morini, E.; Castellani, B.; Presciutti, A.; Filipponi, M.; Nicolini, A.; Rossi, F. Optic-energy performance improvement of exterior paints for buildings. Energy Build. 2017, 139, 690-701. [CrossRef]

70. Levinson, R.; Chen, S.; Ferrari, C.; Berdahl, P.; Slack, J. Methods and instrumentation to measure the effective solar reflectance of fluorescent cool surfaces. Energy Build. 2017, 152, 752-765. [CrossRef]

71. ASTM C1371-15-Standard Test Method for Determination of Emittance of Materials Near Room Temperature Using Portable Emissometers; ASTM International: West Conshohocken, PA, USA, 2015.

72. Devices \& Services, Co. ,DES Technical Note 10-2—Slide Method for High Emittance Materials with Low Thermal Conductivity; Devices \& Services Co.: Dallas, TX, USA, 2010. Available online: https://www.devicesandservices.com/TechNotes/TN10-2.pdf (accessed on 1 August 2021).

73. EN 15976:2011—Flexible Sheets for Waterproofing—Determination of Emissivity, 2011; European Committee for Standardization (CEN): Brussels, Belgium, 2011.

74. Voogt, J.; Oke, T. Thermal remote sensing of urban climates. Remote Sens. Environ. 2003, 86, 370-384. [CrossRef]

75. Brivio, P.A.; Lechi, G.; Zilioli, E. Principi e Metodi di Telerilevamento, 1st ed.; Cittàstudi Edizioni: Torino, Italy, 2006.

76. Baldinelli, G.; Bonafoni, S.; Anniballe, R.; Presciutti, A.; Gioli, B.; Magliulo, V. Spaceborne detection of roof and impervious surface albedo: Potentialities and comparison with airborne thermography measurements. Sol. Energy 2015, 113, 281-294. [CrossRef]

77. Sliuzas, R.; Kuffer, M.; Masser, I. The spatial and temporal nature of urban objects. In Remote Sensing and Digital Image Processing; Rashed, T., Jurgens, C., Eds.; Springer: Dordrecht, The Netherlands, 2010; pp. 67-84.

78. Welch, R. Spatial resolution requirements for urban studies. Int. J. Remote Sens. 1982, 3, 139-146. [CrossRef]

79. Jensen, J.; Cowen, D. Remote sensing of urban suburban infrastructure and socio-economic attributes. Photogramm. Eng. Remote Sens. 1999, 65, 611-622.

80. Herold, M.; Gardner, M.E.; Roberts, D.A. Spectral resolution requirements for mapping urban areas. IEEE Trans. Geosci. Remote Sens. 2003, 41, 1907-1919. [CrossRef]

81. Herold, M.; Roberts, D.A.; Gardner, M.E.; Dennison, P.E. Spectrometry for urban area remote sensing-Development and analysis of a spectral library from 350 to $2400 \mathrm{~nm}$. Remote Sens. Environ. 2004, 91, 304-319. [CrossRef]

82. Brest, C.L.; Goward, S.N. Deriving surface albedo measurements from narrow band satellite data. Int. J. Remote Sens. 1987, 8, 351-367. [CrossRef]

83. Liang, S. Narrowband to broadband conversions of land surface albedo I: Algorithms. Remote Sens. Environ. 2001, 76, 213-238. [CrossRef]

84. Silva, B.B.D.; Braga, A.C.; Braga, C.C.; de Oliveira, L.M.; Montenegro, S.M.; Barbosa, B. Procedures for calculation of the albedo with OLI-Landsat 8 images: Application to the Brazilian semi-arid. Rev. Bras. De Eng. Agríc. Ambient. 2016, 20, 3-8. [CrossRef] 
85. Liang, S.; Shuey, C.J.; Russ, A.L.; Fang, H.; Chen, M.; Walthall, C.L.; Daughtry, C.S.T.; Hunt, R., Jr. Narrowband to broadband conversions of land surface albedo: II. Validation. Remote Sens. Environ. 2003, 84, 25-41. [CrossRef]

86. Menenti, M.; Bastiaanssen, W.G.M.; van Eick, D. Determination of Surface Hemispherical Reflectance with Thematic Mapper Data. Remote Sens. 1989, 28, 327-337. [CrossRef]

87. Akdim, N.; Alfieri, S.M.; Habib, A.; Choukri, A.; Cheruiyot, E.; Labbassi, K.; Menenti, M. Monitoring of irrigation schemes by remote sensing: Phenology versus retrieval of biophysical variables. Remote Sens. 2014, 6, 5815-5851. [CrossRef]

88. Kaplan, S.; Galletti, C.S.; Chow, W.T.L.; Myint, S.W. First order approximation of Broadband Directional Albedo with High Resolution Quickbird Imagery: A case study for arid urban areas. GIScience Remote Sens. 2016, 53, 303-319. [CrossRef]

89. Kuester, M. Radiometric Use of WorldView-3 Imagery; Tech. Note; DigitalGlobe: Longmont, CO, USA, 2016 ; p. 12.

90. Mogili, U.R.; Deepak, B.B.V.L. Review on application of drone systems in precision agriculture. Procedia Comput. Sci. 2018, 133, 502-509. [CrossRef]

91. Fawcett, D.; Panigada, C.; Tagliabue, G.; Boschetti, M.; Celesti, M.; Evdokimov, A.; Biriukova, K.; Colombo, R.; Miglietta, F.; Rascher, U.; et al. Multi-Scale Evaluation of Drone-Based Multispectral Surface Reflectance and Vegetation Indices in Operational Conditions. Remote Sens. 2020, 12, 514. [CrossRef]

92. Park, H.G.; Yun, J.P.; Kim, M.Y.; Jeong, S.H. Multichannel Object Detection for Detecting Suspected Trees with Pine Wilt Disease Using Multispectral Drone Imagery. IEEE J. Sel. Top. Appl. Earth Obs. Remote Sens. 2021, 14, 8350-8358. [CrossRef]

93. Viljanen, N.; Honkavaara, E.; Näsi, R.; Hakala, T.; Niemeläinen, O.; Kaivosoja, J. A novel machine learning method for estimating biomass of grass swards using a photogrammetric canopy height model, images and vegetation indices captured by a drone. Agriculture 2018, 8, 70. [CrossRef]

94. Chabot, D.; Dillon, C.; Shemrock, A.; Weissflog, N.; Sager, E.P. An object-based image analysis workflow for monitoring shallow-water aquatic vegetation in multispectral drone imagery. ISPRS Int. J. Geo-Inf. 2018, 7, 294. [CrossRef]

95. Tóth, V.Z.; Grósz, J.; Ladányi, M.; Jung, A. A new lake algae detection method supported by a drone-based multispectral camera. Lakes Reserv. Res. Manag. 2021, 26, e12377. [CrossRef] 